IUCrJ

ISSN 2052-2525

NEUTRON|SYNCHROTRON

Received 14 June 2016

Accepted 17 October 2016

Edited by V. T. Forsyth, Institut Laue-Langevin, France, and Keele University, UK

Keywords: neutron crystallography; Protein Crystallography Station; Los Alamos Neutron Scattering Center; $\mathrm{H}$ atoms; enzyme mechanisms.

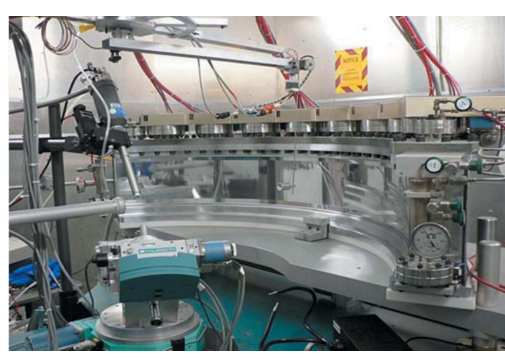

OPEN $\odot$ ACCESS

\section{Fifteen years of the Protein Crystallography Station: the coming of age of macromolecular neutron crystallography}

\author{
Julian C.-H. Chen ${ }^{\mathrm{a}, \mathrm{b} *}$ and Clifford J. Unkefer ${ }^{\mathrm{a}}$
}

a'Bioscience Division, Protein Crystallography Station, Los Alamos National Laboratory, Los Alamos, NM 87545, USA,
and ${ }^{\mathbf{b}}$ Department of Chemistry and Biochemistry, The University of Toledo, Toledo, OH 43606, USA. *Correspondence
e-mail: chen_j@lanl.gov

The Protein Crystallography Station (PCS), located at the Los Alamos Neutron Scattering Center (LANSCE), was the first macromolecular crystallography beamline to be built at a spallation neutron source. Following testing and commissioning, the PCS user program was funded by the Biology and Environmental Research program of the Department of Energy Office of Science (DOE-OBER) for 13 years (2002-2014). The PCS remained the only dedicated macromolecular neutron crystallography station in North America until the construction and commissioning of the MaNDi and IMAGINE instruments at Oak Ridge National Laboratory, which started in 2012. The instrument produced a number of research and technical outcomes that have contributed to the field, clearly demonstrating the power of neutron crystallography in helping scientists to understand enzyme reaction mechanisms, hydrogen bonding and visualization of $\mathrm{H}$-atom positions, which are critical to nearly all chemical reactions. During this period, neutron crystallography became a technique that increasingly gained traction, and became more integrated into macromolecular crystallography through software developments led by investigators at the PCS. This review highlights the contributions of the PCS to macromolecular neutron crystallography, and gives an overview of the history of neutron crystallography and the development of macromolecular neutron crystallography from the 1960s to the 1990s and onwards through the 2000s.

\section{1. $\mathrm{H}$ atoms in macromolecules and neutron scattering}

Nearly one-half of all atoms in a macromolecule are $\mathrm{H}$ atoms, and these $\mathrm{H}$ atoms play essential roles in macromolecular structure and catalysis. Hydrogen bonds are one of the most basic of intermolecular and intramolecular interactions. They are critical components of protein secondary structure, forming the basis for $\alpha$-helices and $\beta$-sheets. In nucleic acids, base pairing is mediated by hydrogen bonds. Hydrogen bonds between ligand or solvent molecules and proteins are key parts of the entropic and enthalpic terms that define the strength and stability of molecular interactions. Despite their importance, however, $\mathrm{H}$ atoms are very difficult to visualize experimentally in X-ray crystal structures; as a result, their positions are usually assumed and modeled. Furthermore, species such as $\mathrm{H}^{+}$and highly polarized $\mathrm{H}$ atoms, and mobile $\mathrm{H}$ atoms with relatively high $B$ factors, often found in enzyme active sites, are invisible to X-rays.

$\mathrm{X}$-ray scattering is proportional to the number of electrons in the system. A heavy atom, such as iron (26 electrons), will 
Table 1

Neutron scattering properties of selected elements in biological systems. $1 \mathrm{fm}=10^{-15} \mathrm{~m} .1$ barn $=10^{-24} \mathrm{~cm}^{2}$.

\begin{tabular}{llll}
\hline & Neutron scattering & $\begin{array}{l}\text { Neutron coherent } \\
\text { scattering cross- } \\
\text { section (barns) }\end{array}$ & $\begin{array}{l}\text { Neutron incoherent } \\
\text { scattering cross- } \\
\text { section (barns) }\end{array}$ \\
\hline${ }^{1} \mathrm{H}$ & -3.74 & 1.76 & 80.27 \\
${ }^{2} \mathrm{H}(\mathrm{D})$ & +6.67 & 5.59 & 2.05 \\
$\mathrm{C}$ & +6.65 & 5.55 & 0.001 \\
$\mathrm{~N}$ & +9.36 & 11.0 & 0.5 \\
$\mathrm{O}$ & +5.80 & 4.23 & 0.0008 \\
$\mathrm{P}$ & +5.13 & 3.31 & 0.005 \\
$\mathrm{~S}$ & +2.85 & 1.02 & 0.007 \\
$\mathrm{Na}$ & +3.63 & 1.66 & 1.62 \\
$\mathrm{Mg}$ & +5.37 & 3.63 & 0.08 \\
$\mathrm{~K}$ & +3.67 & 1.69 & 0.27 \\
$\mathrm{Ca}$ & +4.70 & 2.78 & 0.05 \\
$\mathrm{Mn}$ & -3.73 & 1.75 & 0.4 \\
$\mathrm{Fe}$ & +9.45 & 11.22 & 0.4 \\
$\mathrm{Co}$ & +2.49 & 0.779 & 4.8 \\
$\mathrm{Ni}$ & +10.3 & 13.3 & 5.2 \\
$\mathrm{Cu}$ & +7.72 & 7.48 & 0.55 \\
$\mathrm{Zn}$ & +5.68 & 4.05 & 0.077 \\
$\mathrm{Mo}$ & +6.71 & 5.67 & 0.04 \\
$\mathrm{~W}$ & +4.86 & 2.97 & 1.63 \\
\end{tabular}

thus scatter electrons far more strongly than will hydrogen (one electron). Locating $\mathrm{H}$ atoms in a protein is very difficult, as the scattering contribution from $\mathrm{H}$ atoms is overshadowed by that from neighboring heavier atoms. In the case of proteins, $\mathrm{H}$ atoms are normally bonded to $\mathrm{C}, \mathrm{N}, \mathrm{O}$ and $\mathrm{S}$ atoms, or found in water molecules tightly associated with the protein. Ultrahigh-resolution X-ray structures, diffracting to better than $1.2 \AA$ resolution, have the ability to determine a limited number of $\mathrm{H}$-atom positions, normally appearing as $F_{\mathrm{o}}-F_{\mathrm{c}}$ difference peaks. In practice, even in the highest resolution macromolecular structures reported, such as the high-potential iron-sulfur protein from Thermochromatium tepidum at $0.48 \AA$ resolution (PDB entry $5 \mathrm{~d} 8 \mathrm{v}$; Hirano et al., 2016), and crambin, reported at $0.48 \AA$ resolution (PDB entry 3nir; Schmidt et al., 2011), with a recent data set collected to $0.38 \AA$ resolution (Rosenbaum et al., 2015), it is possible to locate only about two-thirds of the $\mathrm{H}$ atoms in a particular structure. Most of these visible $\mathrm{H}$ atoms are in well ordered regions of the protein. $\mathrm{H}$ atoms in solvent molecules associated with proteins are normally invisible, although they often play critical functional roles. Similarly, $\mathrm{H}$ atoms in active sites are often mobile and cannot be visualized in X-ray structures.

Unlike X-rays, which interact with the electron cloud surrounding the atom, neutrons interact with the atomic nuclei themselves. Generally speaking, while neutrons are scattered by the elements in the periodic table to a similar extent, they can exhibit strong isotope discrimination (https:// www.ncnr.nist.gov/resources/n-lengths/). Of relevance to macromolecular crystallography, hydrogen has two stable isotopes, ${ }^{1} \mathrm{H}$ and ${ }^{2} \mathrm{H}$ (D), which scatter neutrons in a very different manner (Table 1). The neutron scattering length of ${ }^{1} \mathrm{H}$ is $-3.74 \mathrm{fm}$, and there is a large incoherent scattering crosssection, which leads to high noise in neutron scattering. Deuterium (D) has a neutron scattering length of $+6.67 \mathrm{fm}$, which is on a par with other heavier elements found in macromolecules, such as $\mathrm{C}, \mathrm{N}, \mathrm{O}$ and $\mathrm{P}$. This property renders $\mathrm{D}$ atoms visible even at moderate resolution $(2.5 \AA$ and better). By exchanging labile $\mathrm{H}$ atoms for $\mathrm{D}$ atoms and assaying their relative occupancies, it is also possible to obtain a map of the dynamics of proteins within the crystalline environment. Furthermore, by assaying the relative occupancy of $\mathrm{H}$ and $\mathrm{D}$ in critical amino acids, it is also possible to obtain information about the local environments in enzyme active sites and the protonation states of amino acids and solvent molecules in the active sites. This allows the mechanism of enzymes to be much better understood. This has arguably been the major contribution of macromolecular neutron crystallography, with the structures of metalloenzymes and several classes of proteases solved using neutron diffraction.

Neutron and X-ray crystallography are complementary methods for structure-function studies of macromolecules, with X-rays useful in the location of heavy atoms and neutrons useful in determining the location of $\mathrm{H}$ atoms and in inferring dynamics.

As noted, the elements have roughly similar neutron scattering properties across the periodic table (Table 1). In theory, this means that $\mathrm{H}$ atoms are more straightforward to locate, which allows the possibility of properly orienting solvent molecules within a structure. However, as neutrons interact with atomic nuclei, the very small size of atomic nuclei compared with the size of the electron cloud surrounding the atom makes the probability of a productive interaction very low. Neutron fluxes at current sources are exceedingly low $\left(2 \times 10^{6} \mathrm{n} \mathrm{cm}^{-2} \mathrm{~s}^{-1}\right.$ on the sample at the PCS) compared with third-generation synchrotron facilities such as the APS, NSLS-II and MAX IV $\left(10^{11}-10^{13}\right.$ photons s $\left.^{-1}\right)$. Furthermore, as uncharged particles, neutrons are difficult to detect. Only a small number of elements and isotopes have sufficient crosssections to detect interactions with neutrons, e.g. ${ }^{3} \mathrm{He}$ and ${ }^{10} \mathrm{~B}$, and secondary reactions are required to generate a measurable phenomenon (light, charge). These factors all contribute to exceptional sample requirements for neutron crystallography, such as large sample sizes and long measurement times, making it a technically demanding endeavor. For protein crystals, purification of gram quantities of the protein is often needed. For neutron crystallography, protein crystals of greater than $0.1 \mathrm{~mm}^{3}$ in size are preferred, 4-5 orders of magnitude larger than those used in synchrotron data collection. Measurement times range from days to months at neutron sources, compared with less than 15 min for a typical synchrotron X-ray diffraction data set (Munshi et al., 2012). The number of instruments worldwide has also been a limitation. For many years, the only suitable instruments were located at Brookhaven, the National Institute of Standards and Technology (NIST) and the Institut Laue-Langevin (ILL) in Grenoble, with no protein crystallography stations after the closure of the High Flux Beam Reactor (HFBR) at Brookhaven until the commissioning of the LADI instrument at ILL in the mid-1990s. Nevertheless, investments in improving neutron crystallography over the past two decades have led to major advances with regards to sample requirements and 
data-collection times, in addition to more beam time and instruments being available.

\section{A brief history of macromolecular neutron crystallography}

Several comprehensive reviews of macromolecular neutron crystallography have been published in the last few years (Blakeley, 2009; Schoenborn, 2010; Niimura \& Podjarny, 2011; Blakeley et al., 2015); however, a few relevant milestones over the past 50 years are presented here. The 1960s, more than 20 years after the first recorded neutron diffraction from small-molecule crystals, saw the first application of neutron diffraction to protein crystals in a study on the iron-storage protein myoglobin by Benno Schoenborn, who was initially working at the Medical Research Council Laboratory of Molecular Biology (MRC) in the laboratory of John Kendrew (a Nobel Prize winner in 1962) and then later at Brookhaven National Laboratory. The myoglobin data were measured at
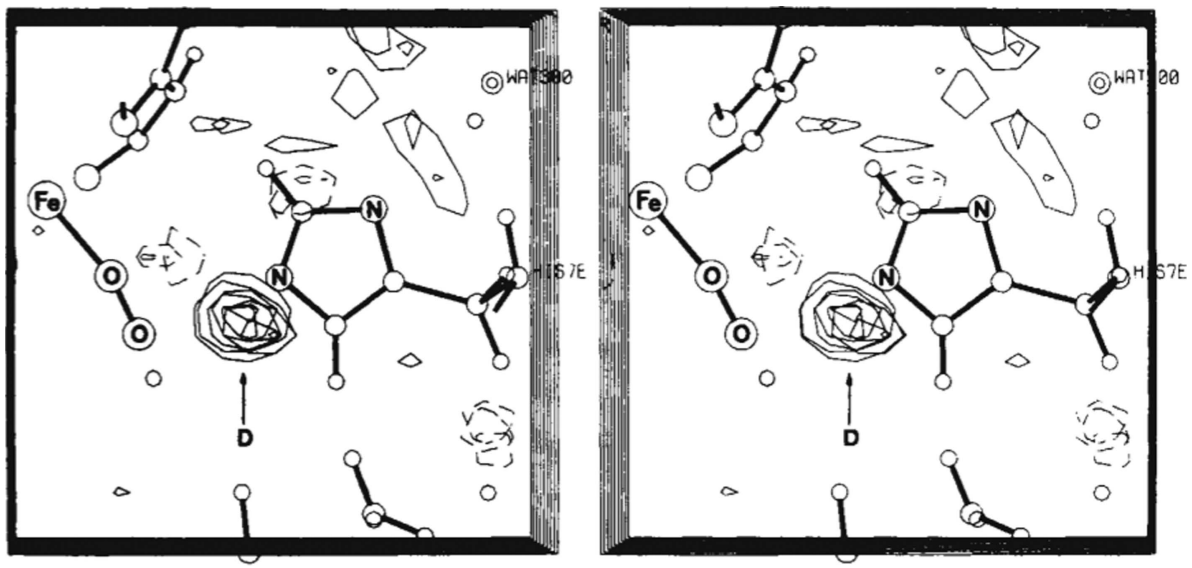

Figure 1

Difference nuclear density demonstrating the protonation of $\mathrm{N}^{\eta}$ of the heme-coordinating histidine in myoglobin. Reprinted with permission from Nature Publishing Group: Phillips \& Schoenborn (1981), Nature (London), 292, 81-82. Copyright (1981) Nature Publishing Group. the HFBR at Brookhaven. It took nearly a year to record 4800 reflections, yielding a $2.8 \AA$ resolution map that clearly showed the protonation of the $\mathrm{N}^{\eta}$ of the imidazole ring on the histidine, coordinating the $\mathrm{FeO}_{2}$ in oxymyoglobin (Fig. 1; Schoenborn, 1969; Phillips \& Schoenborn, 1981).

The first neutron structures of enzymes, ribonuclease A and trypsin, appeared in 1980 (Wlodawer, 1980; Kossiakoff \& Spencer, 1980). Trypsin is a prototypical serine protease, a family of universal enzymes that rely on a catalytic triad generally composed of Ser/His/Asp. In human systems, trypsin plays major roles in digestion, but also in cellular processes that, when misregulated, lead to disease states such as cancer. Tony Kossiakoff collected neutron diffraction data at the Brookhaven HFBR, using a single large $\left(\sim 1 \mathrm{~mm}^{3}\right)$ crystal of monoisopropylphosphoryl-trypsin (MIP-trypsin) that had been soaked in deuterated mother liquor for nearly ten years. The neutron structure showed unambiguously that histidine residue 57 (His57) of the catalytic triad (Ser/His/Asp) was doubly protonated, and that the serine residue had a significantly altered $\mathrm{p} K_{\mathrm{a}}$ value, which allowed it to function as a potent nucleophile in the chemical environment of the enzyme active site (Fig. 2; Kossiakoff \& Spencer, 1981).

A diffractometer was also available at the reactor source at NIST in Gaithersburg, Maryland, USA. Prince, Santoro and Wlodawer modified an existing diffractometer with a positionsensitive ${ }^{3} \mathrm{He}$-based detector (Prince et al., 1978). Wlodawer and coworkers published neutron structures of ribonuclease A (Wlodawer, 1980; Wlodawer et al., 1983; Wlodawer \& Sjölin, 1983), bovine pancreatic trypsin inhibitor (BPTI; Wlodawer et al., 1984) and insulin (Wlodawer et al., 1989).

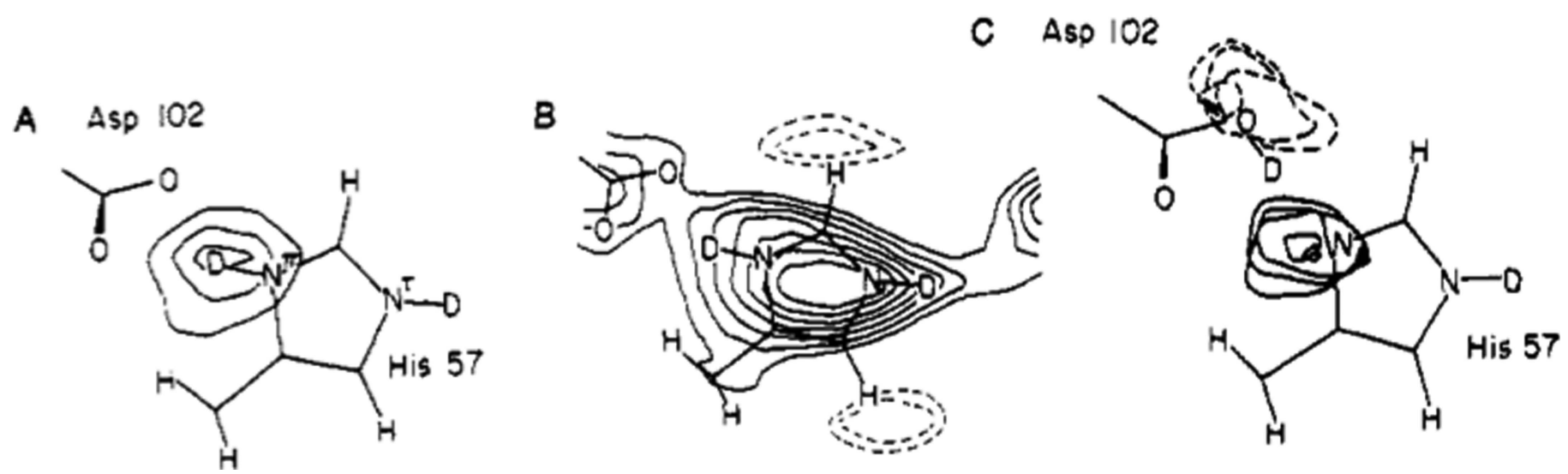

Figure 2

Nuclear density map showing protonation of His57 in trypsin. Left, difference density map showing protonation of $\mathrm{N}^{\delta}$ of His 57. Center, $2 F_{\mathrm{o}}-F_{\mathrm{c}}$ nuclear density map with double protonation of His57 and negative density peaks for the unexchanged $\mathrm{H}$ atoms. Right, difference density map with the proton modeled on Asp102. The contour shows that the proton belongs on His57 (solid lines) and not Asp102 (dotted lines). Reprinted with permission from Kossiakoff \& Spencer (1981), Biochemistry, 20, 6462-6474. Copyright (1981) American Chemical Society. 
Recognizing that neutron data were often incomplete and weak, Wlodawer and Hendrickson developed methods of using X-ray diffraction data in parallel with neutron data to aid in the refinement of the structures (Wlodawer \& Hendrickson, 1982).

In Europe, neutron diffraction studies on the triclinic form of lysozyme, focusing on the binding of solvents such as ethanol and DMSO, were performed on the D8 and D19 instruments at the Institut Laue-Langevin reactor facility (Lehmann \& Stansfield, 1989; Lehmann et al., 1985). The structure of the vitamin $\mathrm{B}_{12}$ coenzyme and its solvent structure were also studied by neutron diffraction using the D8 instrument (Savage, 1986; Langan et al., 1999).

Wlodawer, Kossiakoff and others also used neutron crystallography to study the dynamics of proteins in a crystalline environment, taking advantage of the different scattering properties of the $\mathrm{H}$ and $\mathrm{D}$ isotopes, and monitoring the degree of $\mathrm{H} / \mathrm{D}$ exchange in the protein amide backbone (Wlodawer \& Sjölin, 1982; Kossiakoff, 1982, 1984; Mason et al., 1984). By utilizing H/D exchange at exchangeable hydrogen positions in side chains, it was possible to determine the conformations of methyl rotors and tyrosine hydroxyl groups, indicating that the hydrogen positions were much more constrained than originally thought (Kossiakoff \& Shteyn, 1984; Kossiakoff et al., 1990). By using $\mathrm{D}_{2} \mathrm{O}-\mathrm{H}_{2} \mathrm{O}$ difference maps, it became possible to determine and orient the conformations of solvent molecules hydrating the protein structure (Harrison et al., 1988; Kossiakoff et al., 1992; Finer-Moore et al., 1992; Bon et al., 1999). These were fundamental findings about protein structure and side-chain conformations that have been useful in many disciplines, including computational chemistry, molecular dynamics, drug design and quantum chemistry (McDowell \& Kossiakoff, 1995).
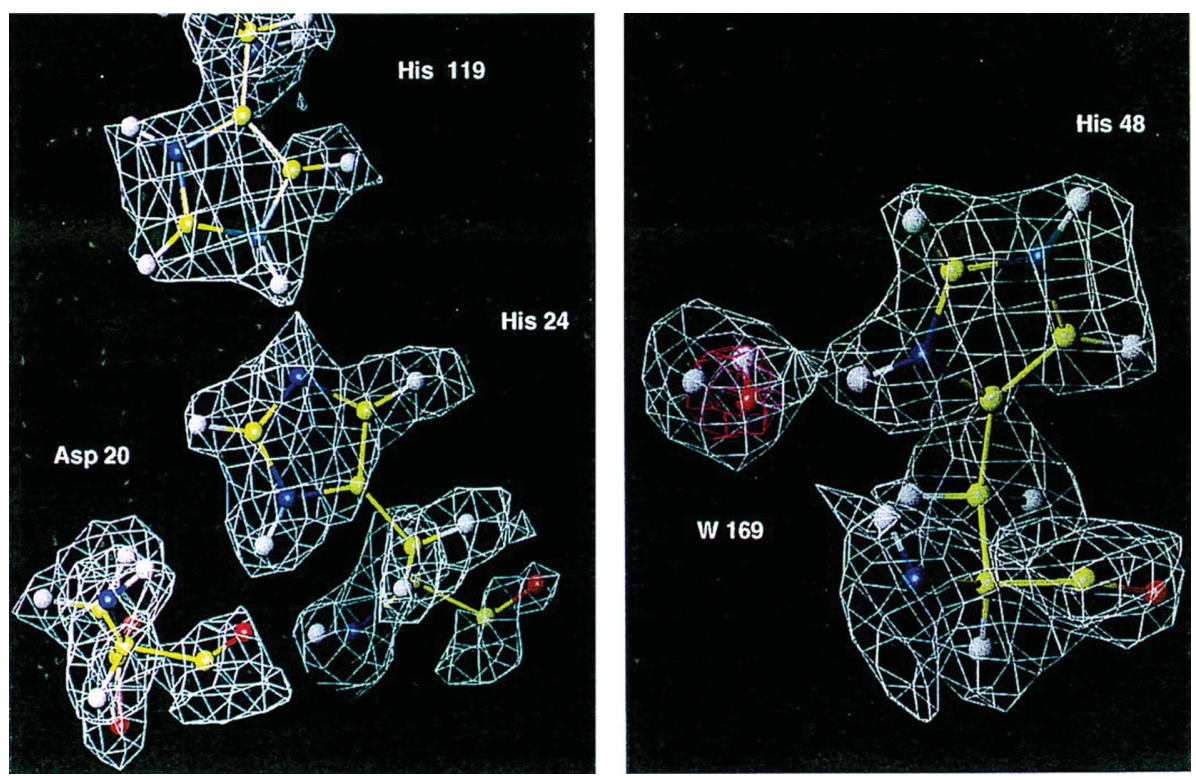

Figure 3

Nuclear density for perdeuterated myoglobin, showing positive density for nonexchangeable H (D) atoms. Reprinted with permission from Shu et al. (2000), Proc. Natl Acad. Sci. USA, 97, 3872-3877. Copyright (2000) National Academy of Sciences.
The HFBR at Brookhaven was shut down between 1989 and 1991, and again starting in 1997, before being permanently closed in 1999. Benno Schoenborn was recruited to Los Alamos National Laboratory (LANL) in 1993 to design and inaugurate a new macromolecular neutron crystallography station at the Lujan Center spallation neutron source. In Europe, the reactor at the Institut Laue-Langevin (ILL) in Grenoble was shut down for a five-year period starting in 1990. During this time, the LADI instrument was upgraded to a neutron imaging plate and was used for data collection after the restart of the reactor in 1995 (Niimura et al., 1997; Langan et al., 1999). As such, little neutron protein crystallography work was conducted during the early 1990s; however, advances in molecular biology and automation revolutionized macromolecular X-ray crystallography during this decade and led to a resurgence of interest in neutron crystallography.

Until the early 1990s, all reported macromolecular neutron structures utilized protein isolated from natural sources. The advent of commercialized molecular biology and new tools for the overexpression of proteins of interest in Escherichia coli facilitated the attainment of the large quantities of purified protein needed for neutron crystallography. The first neutron structure reported using recombinantly expressed protein was a subtilisin $\mathrm{BPN}^{\prime}$ mutant (Kossiakoff et al., 1991). Production of fully deuterated (perdeuterated) proteins also relied on molecular biology and knowledge of bacterial biosynthetic pathways. Perdeuterated staphylococcal nuclease and myoglobin were expressed for the purposes of neutron crystallography (Gamble et al., 1994; Shu et al., 1996), leading to a neutron structure of perdeuterated myoglobin as a proof of principle (Fig. 3; Shu et al., 2000).

In the 1990s, macromolecular X-ray crystallography was becoming increasingly streamlined through hardware (synchrotrons, fast-readout CCD detectors, robotics, cryocooling), software (integrated crystallographic refinement programs) and easily accessible crystallization (high-throughput screening, ready-made crystallization screening kits). These developments opened up a wide range of proteins for structural biology studies, and helped drive a new demand for neutron diffraction instruments and more efficient data collection.

The Protein Crystallography Station (PCS) was designed and built to address these difficult problems, offering a stateof-the-art, high-efficiency detector located at a pulsed spallation neutron source to reduce sample-measurement times through the production of a spectrum of resolvable time-of-flight (TOF) neutrons (Langan \& Greene, 2004; Langan et al., 2004, 2008). Initial design of the instrument was completed in November 1996 (Schoenborn, 1996), 
Table 2

Structures in the PDB collected at the PCS.

\begin{tabular}{|c|c|c|c|c|c|c|}
\hline Protein & Unit-cell parameters $\left(\AA{ }^{\circ}\right)$ & $\begin{array}{l}\text { Space } \\
\text { group }\end{array}$ & $\begin{array}{l}\text { Resolution } \\
(\AA)\end{array}$ & $\begin{array}{l}\text { PDB } \\
\text { code }\end{array}$ & $\begin{array}{l}\text { Crystal } \\
\text { volume }\left(\mathrm{mm}^{3}\right)\end{array}$ & Primary citation \\
\hline Amicyanin & $a=27.5, b=56.6, c=28.9, \beta=96.2$ & $P 2_{1}$ & 1.8 & 3145 & 2.6 & Sukumar et al. (2010) \\
\hline CA-acetazolamide & $a=42.8, b=41.8, c=72.9, \beta=104.3$ & $P 2_{1}$ & 2.0 & $4 \mathrm{~g} 0 \mathrm{c}$ & 2.0 & Fisher et al. (2012) \\
\hline CA, pH 7.8 & $a=42.8, b=41.7, c=72.9, \beta=104.6$ & $P 2_{1}$ & 2.0 & 3 tmj & 1.7 & Fisher et al. (2011) \\
\hline CA, pH 9.0 & $a=42.6, b=41.6, c=72.8, \beta=104.6$ & $P 2_{1}$ & 2.0 & $3 \mathrm{kkx}$ & 1.2 & Fisher et al. (2010) \\
\hline CA apo, low pH & $a=42.7, b=41.7, c=72.9, \beta=104.7$ & $P 2_{1}$ & 2.0 & $4 \mathrm{y} 0 \mathrm{j}$ & 2.0 & Michalczyk et al. (2015) \\
\hline Crambin & $a=22.8, b=18.8, c=41.0, \beta=90.9$ & $P 2_{1}$ & 1.1 & $4 \mathrm{fc} 1$ & 4.0 & Chen et al. (2012) \\
\hline DHFR-methotrexate & $a=b=93.1, c=73.9$ & $P 6_{1}$ & 2.17 & 2inq & 0.3 & Bennett et al. (2006) \\
\hline DFPase & $a=43.4, b=83.3, c=87.5$ & $P 2_{1} 2_{1} 2_{1}$ & 2.2 & 3byc & 0.43 & Blum et al. (2009) \\
\hline Endothiapepsin & $a=43.0, b=75.7, c=43.0, \beta=97.0$ & $P 2_{1}$ & 2.0 & $2 v s 2$ & & Coates et al. (2008) \\
\hline Z-DNA & $a=17.9, b=30.6, c=44.6$ & $P 2_{1} 2_{1} 2_{1}$ & 1.4 & $3 q b a$ & 0.7 & Fenn et al. (2011) \\
\hline Deoxyhemoglobin & $a=63.8, b=84.4, c=54.3, \beta=99.3$ & $P 2_{1}$ & 2.0 & $3 \mathrm{kmf}$ & 20 & Kovalevsky et al. (2010) \\
\hline Equine cyanomet hemoglobin & $a=108.9, b=63.2, c=54.7, \beta=110.75$ & $C 2$ & 2.0 & $5 \mathrm{c} 6 \mathrm{e}$ & 10 & Dajnowicz et al. (2016) \\
\hline Photoactive yellow protein & $a=b=66.8, c=40.9$ & $P 6_{3}$ & 2.5 & 2qws & 0.79 & Fisher et al. (2007) \\
\hline XI apoenzyme & $a=93.9, b=99.7, c=102.9$ & $I 222$ & 1.8 & 2gve & 8 & Katz et al. (2006) \\
\hline $\mathrm{XI}-\mathrm{Ni}^{2+}$-linear sugar & $a=94.0, b=99.7, c=102.9$ & $I 222$ & 1.8 & $3 \mathrm{kco}$ & 50 & Kovalevsky et al. (2010) \\
\hline XI-xylulose & $a=94.6, b=100.0, c=104.0$ & $I 222$ & 2.2 & $3 \mathrm{cwh}$ & 4 & Kovalevsky et al. (2008) \\
\hline $\mathrm{XI}-\mathrm{Cd}^{2+}$-cyclic $\beta$-arabinose & $a=93.9, b=99.7, c=103.0$ & $I 222$ & 2.0 & $4 q d p$ & & Langan et al. (2014) \\
\hline XI apo, pH 5.9 & $a=93.9, b=99.5, c=103.0$ & $I 222$ & 2.0 & $3 q z a$ & 9 & Kovalevsky et al. (2011) \\
\hline Xylanase, pD 8.9 & $a=49.6, b=60.0, c=70.5$ & $P 2_{1} 2_{1} 2_{1}$ & 1.7 & $4 \mathrm{~s} 2 \mathrm{~h}$ & 7 & Wan et al. (2015) \\
\hline Xylanase, WT-MES & $a=49.2, b=60.2, c=70.4$ & $P 2_{1} 2_{1} 2_{1}$ & 2.0 & $4 \mathrm{~s} 2 \mathrm{~d}$ & & Wan et al. (2015) \\
\hline Xylanase, N44D mutant & $a=49.2, b=60.3, c=70.5$ & $P 2_{1} 2_{1} 2_{1}$ & 2.0 & $4 x p v$ & & Wan et al. (2015) \\
\hline
\end{tabular}

and the instrument was commissioned in 2001-2002. During the user program of the PCS, a great deal of effort was invested in utilizing deuteration as a means of reducing the sample-size requirement and the measurement times for neutron samples. A deuteration facility was maintained for users to produce fully and partially deuterated proteins for crystallization using E. coli-based expression systems. Although no perdeuterated neutron structures were reported from the PCS, the facility successfully produced several perdeuterated proteins and X-ray structures (Liu et al., 2007; Blum et al., 2010). Neutron diffraction data from perdeuterated and selectively deuterated protein samples have been collected at LADI-III at the ILL (Blakeley et al., 2010) and on the monochromatic instrument D19 (Cuypers et al., 2013, 2016; Haupt et al., 2014), demonstrating that deuteration can clearly shorten data-collection times, reduce the size of suitable crystals and increase the visibility of $\mathrm{H}$ atoms. The protocols and methods employed to deuterate proteins are well documented, have led to successful structure determinations of otherwise difficult targets and have become an essential part of neutron sources worldwide (Hazemann et al., 2005; Petit-Haertlein et al., 2009, 2010; Tomanicek et al., 2011; Howard et al., 2011, 2016; Munshi et al., 2012; Cuypers et al., 2013, 2016; Meilleur et al., 2013; Weber et al., 2013; Haupt et al., 2014; Gerlits et al., 2016; Haertlein et al., 2016). In addition, computational tools were developed to simplify and integrate neutron crystallography into available programs and software suites for streamlined macromolecular crystallography (much of it developed at other DOE facilities). This multidisciplinary approach has effectively revolutionized macromolecular neutron crystallography over the past decade, with the PCS strongly contributing to these developments. To date, this includes 21 structures in the Protein Data Bank (PDB) based on data collected at the PCS (Table 2).
Indeed, the work performed at the PCS during the 13 years of the DOE-funded user program revealed both unexpected and critical data on enzyme mechanisms and highlighted the unique characteristics and chemistry of enzyme active sites. These data have proved to be critical for drug design and protein engineering, and can be utilized with technologies to yield significant human and economic benefits. To date, although structures determined using neutron diffraction still represent a very small fraction (106 structures) of PDB entries ( $\sim 120000$ structures), these structures represent the failure of any other probe, be it X-rays, NMR or the use of electrons, to answer a structural biochemistry question, and which neutron diffraction could provide. Macromolecular neutron crystallography therefore occupies a very special place in structural molecular science.

\section{Description of the Protein Crystallography Station}

The PCS is located on Flight Path 15 (FP15) emanating from Target 1 at the Lujan Center, part of a suite of instruments making use of neutrons produced upon the bombardment of a heavy-metal target with high-energy protons. This process produces neutrons that are ejected from the metal target, called spallation neutrons. Spallation neutrons have a distinct advantage over neutrons produced by a reactor source in that they can be produced in bursts. The produced spallation neutrons vary in energy, with the largest population around 1-3 MeV. The de Broglie equation

$$
\lambda=h /(m v),
$$

where the mass of a neutron $m$ is $1.6749 \times 10^{-27} \mathrm{~kg}$, relates the wavelength and velocity of the neutrons. Over a distance of $28 \mathrm{~m}$, the target-to-detector distance for the PCS, neutrons of wavelength $0.6-6 \AA$ arrive over a period of $4.5-45 \mathrm{~ms}$, with the 
highest energy (shortest wavelength) neutrons arriving at the detector first. With the $20 \mathrm{~Hz}$ pulse frequency, a packet of neutrons is generated from the target every $50 \mathrm{~ms}$, which dictates the design of the flight paths. Nearest the target is a beryllium reflector to direct neutrons towards the beam pipe, and also a water moderator, where the thermal neutrons are generated.

For the PCS, a chopper system selects neutrons in the wavelength range $0.6-6 \AA$ and filters out high-energy, shorterwavelength neutrons and gamma rays that may be potentially damaging to biological systems and that may shorten the lifetime of the samples. The rotation of the chopper is phaselocked with the $20 \mathrm{~Hz}$ pulse frequency of the neutron pulses. The distance from the target to the sample is $28 \mathrm{~m}$. A curved detector, with $120^{\circ}$ of coverage, lies $70 \mathrm{~cm}$ from the sample. To record the highest resolution reflections, the $2 \theta$ arm can be moved, allowing nearly $360^{\circ}$ of coverage. The detector uses ${ }^{3} \mathrm{He}$ to detect neutrons and provides readout in real time (Fig. 4). A more detailed description follows.

\subsection{Target/moderator/reflector/shielding}

A proton beam accelerated to $84 \%$ of the speed of light $(800 \mathrm{MeV})$ bombards a tungsten target, leading to neutrons being ejected from the target. The facility operates at around $100 \mathrm{~kW}$ power. Currently in place at Lujan Center is a fourthgeneration, integrated target/moderator/reflector/shielding assembly (Mark-III TMRS), which was installed in mid-2010 (Fig. 5). The measured neutron flux became threefold higher after target replacement and installation of the Mark-III TMRS, estimated at $2 \times 10^{6} \mathrm{n} \mathrm{cm}^{-2} \mathrm{~s}^{-1}$ (Mocko et al., 2011; Mocko \& Muhrer, 2013; M. Mocko, personal communication). To accommodate the desired spectral characteristics of the suite of instruments, six different moderators are arranged within the unit on two levels, using both liquid $\mathrm{H}_{2}$ and $\mathrm{H}_{2} \mathrm{O}$ as the moderator medium. The target consists of a series of stacked tungsten plates, clad with tantalum to contain the spallation byproducts and cooled with circulating water. For

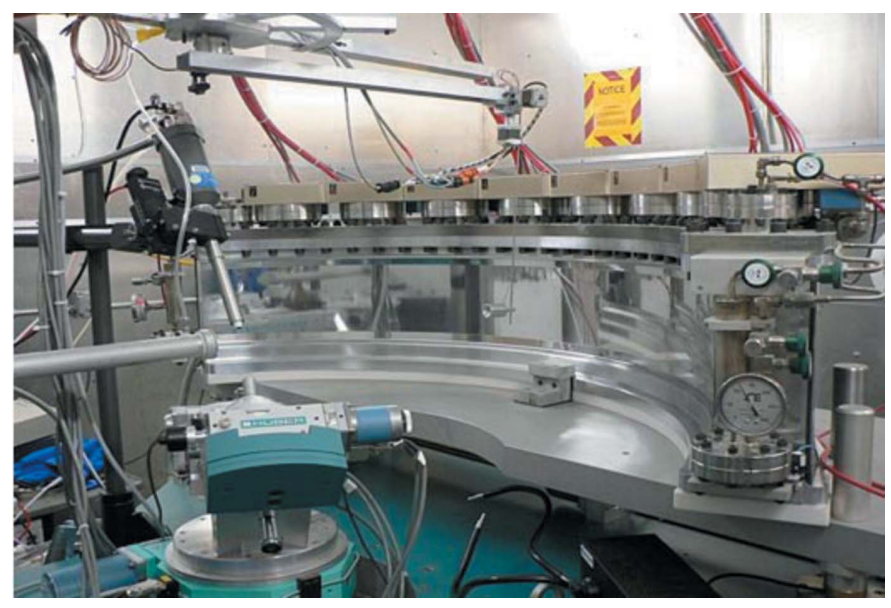

Figure 4

Overview of the PCS detector environment. On the left is the beam pipe, Oxford Cryosystems cryocooling arm and kappa goniometer. On the right is the ${ }^{3} \mathrm{He}$ detector system. the PCS, a coupled water moderator is used, with the water circulated inside a $13 \times 13 \times 4 \mathrm{~cm}$ container and surrounded by a beryllium block that acts as a neutron reflector. The entire TMRS assembly is compact, measuring $60 \mathrm{~cm}$ in diameter and $3 \mathrm{~m}$ in height. This is inserted into a crypt that contains a beam stop and a vacuum steel casing. In turn, the crypt is

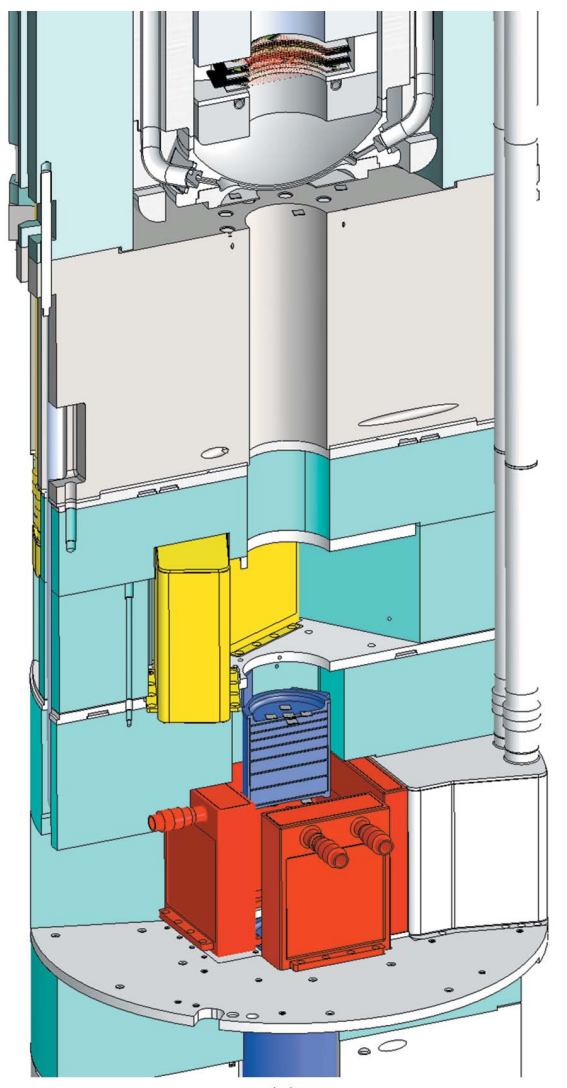

(a)

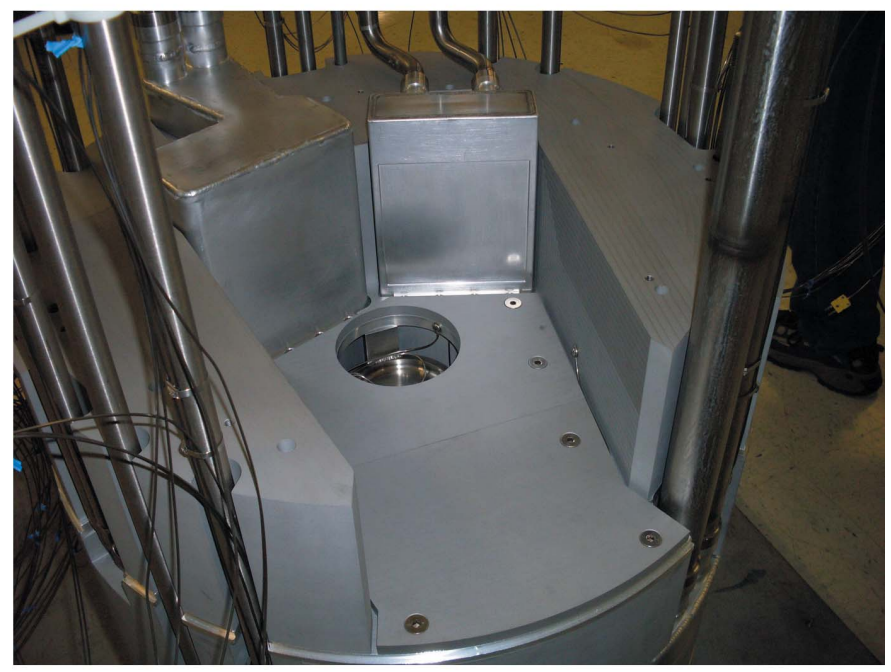

(b)

Figure 5

(a) Schematic of the Mark-III TMRS. Beryllium reflectors are in cyan, tungsten target plates in blue and moderator suites in yellow and red. The proton beam strikes the target from above. (b) Upper moderator suite, with the $\mathrm{H}_{2} \mathrm{O}$ moderator for FP14 and FP15 at the center, a $\mathrm{H}_{2}$ moderator to its left and beryllium reflectors arranged around the moderator. The neutrons for FP15 are directed towards the foreground. 
surrounded by the biological shielding, which extends $3 \mathrm{~m}$. The choice of moderator and reflector is critical; wavelength resolution is achieved at the expense of neutron flux and vice versa. For the PCS, it was important to have a high flux of neutrons, as the relatively long $28 \mathrm{~m}$ flight path and desired crystal diffraction limits could partially offset the ambiguities of wavelength resolution.

\subsection{Shutter, chopper and collimation}

The shutter consists of a mercury reservoir that fills a section of the beam pipe by gravity. The shutter is opened by pumping He gas to move the mercury back into the reservoir, such that the section of the beam pipe is filled with He during data collection. The target, moderator and shutter are all contained within the $3 \mathrm{~m}$ biological shielding surrounding the target. More powerful spallation sources such as the Spallation Neutron Source (SNS; $1 \mathrm{MW}$ ) require thicker shielding.

A composite T0/T1 chopper is located $9.5 \mathrm{~m}$ downstream of the target. It restricts the wavelength of neutrons to the 0.6-6 A range. The T0 component further removes any highenergy neutrons and residual gamma rays that may damage biological samples. The T1 component removes the so-called 'frame overlap', ensuring that the long-wavelength, slowesttraveling neutrons arrive at the detector $(45 \mathrm{~ms})$ before the start of the next neutron pulse $(50 \mathrm{~ms})$.

Normally, T0/T1 choppers are designed on separate rotors. In the case of the PCS, a single blade of $30 \mathrm{~cm}$ thickness and $30 \mathrm{~cm}$ radius acts as the $\mathrm{T} 0$ unit, while the $\mathrm{T} 1$ is the chopper housing that runs under helium to reduce wear on the bearings and is painted with neutron-absorbing boron paint. The rotation of the chopper is synchronized with a $20 \mathrm{~Hz}$ repetition rate of the pulse to stop overlap of radiation from the previous pulse. It is also tuned to the efficiency of the detector (which is highest in the 1-2 $\AA$ range).

The collimation was designed with the intention of producing a neutron beam with a size of $\sim 5 \mathrm{~mm}$ and a divergence of approximately $0.12^{\circ}$, matching that of an average protein crystal at room temperature. This has been accomplished by the placement of 16 boron ceramic disks (scrapers) with circular apertures that gradually narrow the neutron beam from the initial $13 \times 13 \mathrm{~cm}$ size when it exits the moderator. Three disks (boron carbide) are located within the bulk shielding, while the remaining 13 disks (boron nitride) are in the beam pipe. The beam pipe is operated under vacuum.

Additional hardware were proposed, including a focusing mirror and a tail-cutting device for further refinement of the neutron spectrum, but were not constructed (Schoenborn, 1996; Langan et al., 2001).

\subsection{Goniometer, detector and software}

The goniometer is a custom-built Huber model with a quasithree-circle setting, allowing manipulation of the crystal orientation in the $\varphi, \omega$ and $\kappa$ orientations, in addition to the $z$ (vertical) translation. This allows wide sampling of crystal orientations without moving the detector. The goniometer can be controlled from within the hutch and also remotely by
Table 3

Detector specifications.

Source: Brookhaven National Laboratory.

\begin{tabular}{|c|c|}
\hline Active area & $1.5 \mathrm{~m} \times 20 \mathrm{~cm}(8 \mathrm{segments})$ \\
\hline Angular coverage & $120^{\circ}$ (curved) in $x, 15^{\circ}$ in $y$ \\
\hline Radius of curvature at anode $(\mathrm{cm})$ & 72.8 \\
\hline Position-encoding method & Resistive charge division \\
\hline Position-decoding method & $\begin{array}{l}\text { ADC, FPGA and DSP center-of-gravity } \\
\text { calculation }\end{array}$ \\
\hline Event processing time & $\sim 4 \mathrm{~ms}$ per segment \\
\hline Event timing resolution (ms) & $\sim 1$ \\
\hline Rate capability (global) $\left(\mathrm{s}^{-1}\right)$ & $\geq 10^{6}$ \\
\hline Gas mixture & $\overline{7} \mathrm{~atm}{ }^{3} \mathrm{He}+2.5 \mathrm{~atm}$ propane \\
\hline Gas depth $(\mathrm{cm})$ & 1.5 \\
\hline Nominal gas gain & 50 \\
\hline Readout channels & 15 in $x, 16$ in $y$ per segment \\
\hline Readout node spacing $(\mathrm{mm})$ & 12.7 \\
\hline Wire pitch $(\mathrm{mm})$ & 1.6 \\
\hline Position resolution & $1.5 \mathrm{~mm}$ FWHM for thermal neutrons \\
\hline Image size (pixels) & $\begin{array}{l}480 \times 512(245760) \text { per segment, } \\
1966080 \text { total }\end{array}$ \\
\hline Detection efficiency & $\sim 50 \%$ at $1 \AA,>90 \%$ at $4 \AA$ \\
\hline Weight $(\mathrm{kg})$ & $\sim 250$ \\
\hline
\end{tabular}

computer; the data-acquisition software allows multiple frames to be collected using a single command.

The PCS detector is a curved, ${ }^{3} \mathrm{He}$-based, position-sensitive detector offering real-time readout, built by the Instrumentation Division at Brookhaven National Laboratory (Radeka et al., 1996; Mahler et al., 1999; Fried et al., 2002). The detector is among the most versatile in the world. The use of spallation neutrons at $20 \mathrm{~Hz}$ demanded a position-sensitive detector capable of a fast readout. The use of ${ }^{3} \mathrm{He}$ also offers a number of distinct advantages over other neutron concepts, including the more recent scintillation-based designs (Anger cameras) currently in use at facilities such as SNS. The detection efficiency of ${ }^{3} \mathrm{He}$ is very high; single neutron interactions are detectable. The timing resolution of the electronics is $\sim 1 \mathrm{~ms}$. In real terms, on the PCS, with its $28 \mathrm{~m}$ flight path, the wavelength resolution approaches $\sim 0.15 \AA$. The detector is mounted on a table concentric with the goniometer, allowing rotation of the detector by $2 \theta$, in addition to the $z$ (vertical) translation of the detector, which is independent of the $z$ translation of the crystal. These settings allow the detector to be manipulated to collect high-resolution data. The active surface area of the detector is $150 \times 20 \mathrm{~cm}$, split into eight equal segments, spanning an angle of $120^{\circ}$.

The detector uses ${ }^{3} \mathrm{He}$, which interacts with a neutron in the following reaction:

$$
\mathrm{n}+{ }^{3} \mathrm{He} \rightarrow \mathrm{p}+{ }^{3} \mathrm{H}+764 \mathrm{keV}
$$

The ${ }^{3} \mathrm{H}$ and proton are emitted in opposite directions, with the proton carrying the majority of the kinetic energy (573 keV). The proton range is several centimetres, requiring the addition of a stopping gas to achieve the necessary spatial resolution. In the PCS detector, a small amount of propane is added to the ${ }^{3} \mathrm{He}$ chamber, which sharpens the resolution to $\sim 1 \mathrm{~mm}$. The gas mixture is maintained at $\sim 7$ atm ${ }^{3} \mathrm{He}$ and $2.5 \mathrm{~atm}$ propane, a proportion that allows $\sim 50 \%$ neutron detection efficiency at $0.6 \AA$ and approaches $100 \%$ efficiency at $6 \AA$. The gas is 
housed in a special aluminium alloy pressure vessel that yields at $73000 \mathrm{psi}$, with an $8 \mathrm{~mm}$ thick window that minimizes neutron scattering from the vessel materials. Despite the superior neutron-detection properties of ${ }^{3} \mathrm{He}$, it has very low natural abundance $(0.000137 \%)$ and is expensive. The gas mixture is internally circulated and is topped off every five years. The scarcity of ${ }^{3} \mathrm{He}$ has in part driven the development of the scintillation-based detector technologies currently used on the SNS single-crystal instruments. Table 3 lists the specifications of the detector.

Readout in real time is provided by four DAQs. The system was upgraded in mid-2011, using software written by Marat Mustyakimov that allowed computer control of the goniometer. A modified version of $d^{*} T R E K$ is used for data integration and processing, and LAUENORM is utilized for wavelength normalization of the integrated reflections (Helliwell et al., 1989; Pflugrath, 1999; Langan \& Greene, 2004). Software for structure refinement is discussed below (§4.7). The program can combine the time slices into a quasiLaue diffraction pattern. An example of such a pattern is shown in Fig. 6.

\section{Science highlights}

The user program was funded by DOE-OBER from 2002 to 2014, yielding numerous advances in macromolecular neutron crystallography. In this section, a number of science highlights based on the PCS are described. These include the LANL mission-relevant enzymes D-xylose isomerase (XI), carbonic anhydrase (CA) and diisopropyl fluorophosphatase (DFPase), in addition to enzymes of pharmaceutical interest such as dihydrofolate reductase (DHFR) and endothiapepsin, as well as methods-based work on crambin and joint X-ray and neutron refinement. A total of 21 structures using data collected at the PCS have been deposited in the PDB at the time of writing (Table 2).

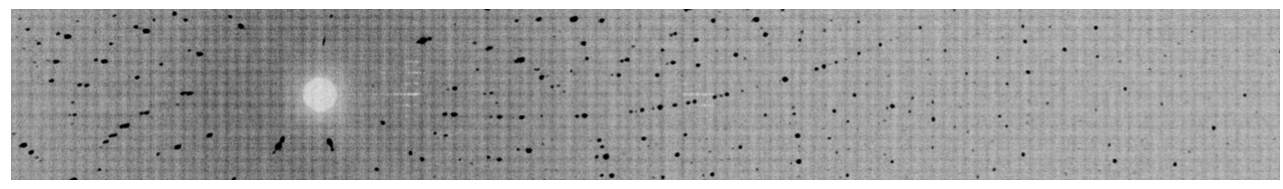

Figure 6

Quasi-Laue projection of time-of-flight neutron diffraction from a crystal of crambin. The detector has been rotated to a $2 \theta$ angle of $30^{\circ}$ to record high-resolution reflections.
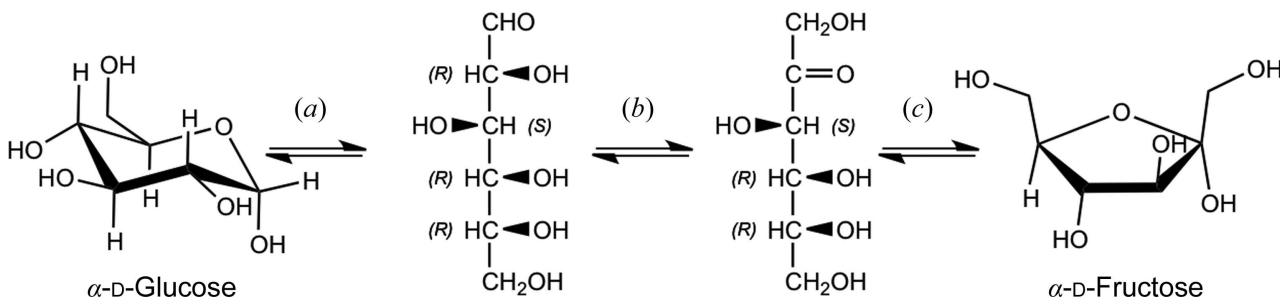

Figure 7

Mechanistic pathway for the isomerization of D-glucose to D-fructose, catalyzed by XI, with ring opening (a) followed by isomerization (b) and ring closing (c) (Kovalevsky et al., 2010).

\subsection{D-Xylose isomerase (XI)}

The PCS has been used to study the mechanisms of two enzymes of importance to DOE programs in biofuels and renewable energy: D-xylose isomerase (XI) and carbonic anhydrase (CA). XI catalyzes the interconversion between the aldo-sugars D-xylose and D-glucose and the keto-sugars D-xylulose and D-fructose, respectively. XI is a commercially important enzyme that is used in the production of soft-drink sweeteners and also in biofuel production. One problem in the efficient use of biomass derived from cellulose is that a significant portion is in the form of xylose, which cannot be fermented by the yeast Saccharomyces cerevisiae in the commercial production of ethanol. On the other hand, D-xylulose can be fermented by $S$. cerevisiae. XI, which is encoded by several fungal and bacterial species, is able to perform this conversion, albeit at a slow rate (Fig. 7). To further harness its commercial potential, and to guide the engineering of XI to increase its activity and to make it an economically feasible methodology, the mechanism of XI has also been extensively studied through structural and functional characterization. Over the last ten years, multiple neutron structures of XI have been solved. The mechanism relies on two divalent metal ions for activity, with a maximal activity around $\mathrm{pH} 8.0$, which is higher than the acidic $(\mathrm{pH}<6)$ conditions of biomass conversion.

In a series of studies since 2006, the PCS was used to collect four different states of the enzyme to study the reaction mechanism of XI, including the apoenzyme (Fig. 8; Katz et al., 2006), a complex of XI with the product D-xylulose (Kovalevsky et al., 2008), XI with nickel and a linear sugar resembling an intermediate (Kovalevsky et al., 2010) and metal-free XI at two $\mathrm{pH}$ values (Kovalevsky et al., 2011). An additional neutron data set was collected at ILL D19 in Grenoble by PCS staff members. Mechanistically, several amino acids, including Asp257, Lys289 and His54, were equivocal in their protonation states even in ultrahigh-resolution X-ray structures. The neutron structures demonstrated that Lys289 was uncharged (deprotonated) and disordered before ring opening and positively charged and ordered after ring opening. His54 was found to be doubly protonated throughout the course of the reaction. The solvent molecule bound to the catalytic metal is found to be water before isomerization and is identified as hydroxide after isomerization. Water orientations and hydrogen bonds are radically shifted during the course of the reaction.

One of the major achievements of this work was the ability to use neutrons to resolve and distinguish between the elusive $\mathrm{H}^{+}$and 
$\mathrm{H}_{3} \mathrm{O}^{+}$species, the former of which contain no electrons and is therefore invisible in X-ray structures and the latter of which is identifiable as a pyramidal $\mathrm{D}_{3} \mathrm{O}^{+}$species in nuclear density maps (but appears as a single $\mathrm{O}$ atom in electron-density maps). The structure of metal-free $\mathrm{XI}$ at $\mathrm{pH} 7.7$ shows a $\mathrm{D}_{3} \mathrm{O}^{+}$ species occupying the site of one of the metals. Under acidic conditions, at $\mathrm{pH} 5.9$, the $\mathrm{D}_{3} \mathrm{O}^{+}$is dehydrated to a $\mathrm{D}^{+}$, with the amino acids collapsing onto the proton (Fig. 9; Kovalevsky et al., 2011).

On a technical level, the unit cell of XI is one of the largest ever resolved using neutron diffraction, crystallizing in space group $I 222$ with unit-cell parameters $a=94, b=100, c=103 \AA$. More recent experiments on another sugar-converting enzyme, levoglucosan kinase, demonstrated resolved diffraction spots from a crystal with a maximum cell edge of $230 \AA$, exceeding the predicted resolving power of the PCS detector.

\subsection{Carbonic anhydrase (CA)}

$\mathrm{CA}$ is crucial for cellular function and also for green chemistry, as a means of carbon sequestration. CA is a ubiquitous enzyme found in all living organisms, supporting a wide variety of physiological processes. It is a zinc metalloenzyme catalyzing the interconversion of carbon dioxide to bicarbonate, with a subsequent proton-transfer step. The proton-transfer step is rate-limiting, the excess proton being transferred via a water wire that stretches between the catalytic $\mathrm{Zn}$ and bulk solvent via His64. Like XI, human CA-II has been extensively studied using neutron crystallography

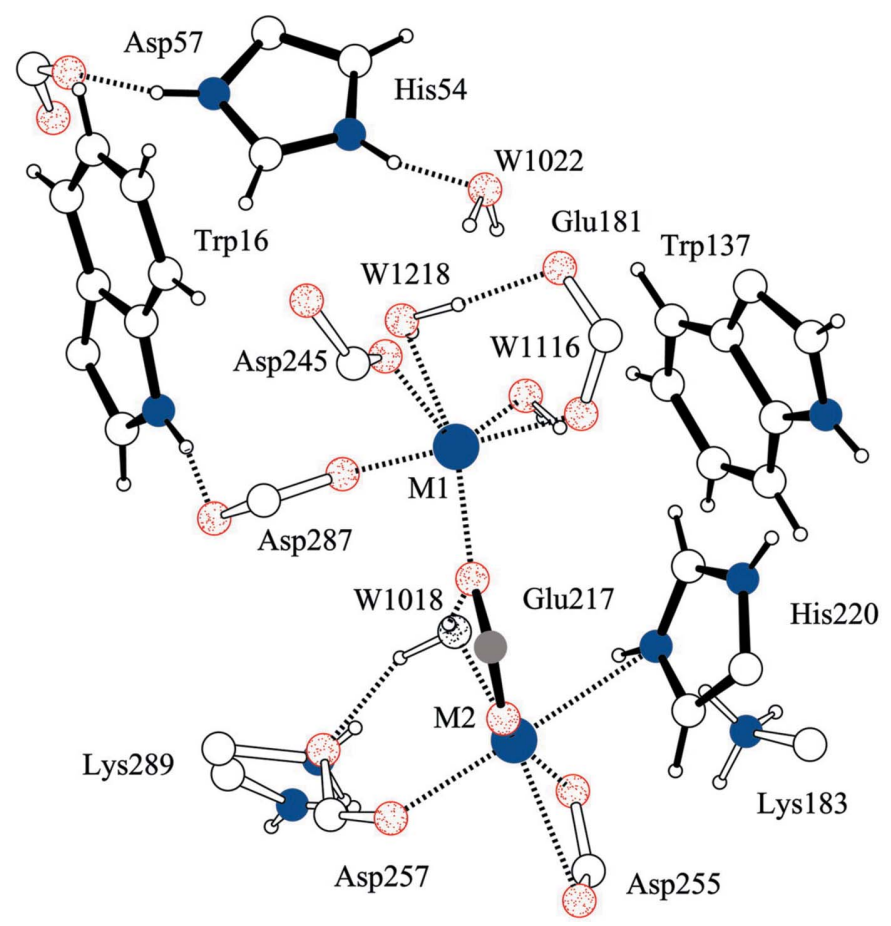

Figure 8

Active-site environment of XI as determined by neutron diffraction, showing the bimetal catalytic center and orientations of water molecules in the vicinity. Reprinted with permission from Katz et al. (2006), Proc. Natl Acad. Sci. USA, 103, 8342-8347. Copyright (2006) National Academy of Sciences.
(Fisher et al., 2010, 2011, 2012; Michalczyk et al., 2015). The enzyme is one of the few that work at an apparent $k_{\text {cat }}$ that is faster than diffusion.

$\mathrm{CA}$ is one of the most extensively studied enzymes using neutron crystallography and a number of critical findings have been discovered that relate to the water relay that moves the excess proton. A single hydrogen bond among a long hydrogen-bonding network was found to act as a switch, explaining the activity of the enzyme at near-neutral and high $\mathrm{pH}$ values. Although the positions of the $\mathrm{O}$ atoms remained constant, the $\mathrm{S}$ atoms were altered in position, and these results could not have been obtained even at the highest X-ray resolutions but were clearly defined using neutron crystallography. Several findings from the neutron structures of CA have important mechanistic implications. A solvent molecule coordinated to the catalytic metal was identified as water and not hydroxide (Fig. 10). Enzyme-active sites are often characterized by residues displaying radically altered $\mathrm{p} K_{\mathrm{a}}$ values and unexpected protonation states. The active-site residue His64 was found to be singly protonated and ready to accept a single proton. The hydroxyl group of Tyr7, a residue that helps

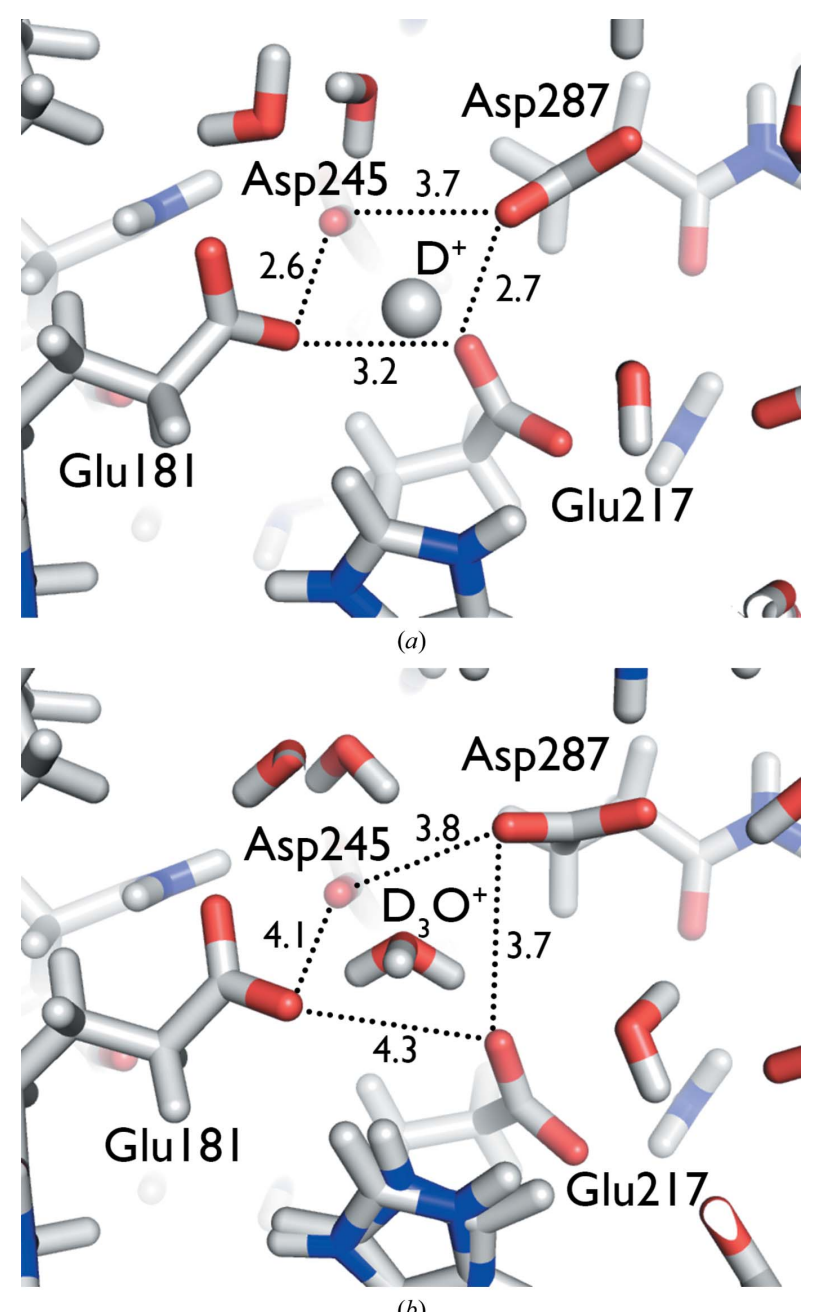

Figure 9

(b)

(a) Interaction of metal-coordinating residues in $\mathrm{XI}$ with $\mathrm{D}^{+}$at $\mathrm{pH} 5.9$ (PDB entry 3qza). (b) Interaction of metal-coordinating residues in XI with $\mathrm{D}_{3} \mathrm{O}^{+}$at $\mathrm{pH} 7.7$ (PDB entry $3 \mathrm{kcj}$ ) (Kovalevsky et al., 2011). 
orient the water network, was found to be deprotonated at $\mathrm{pH}$ 10 , which was lower than expected. In a recent study jointly using NMR spectroscopy and neutron crystallography, the $\mathrm{p} K_{\mathrm{a}}$ of Tyr7 was determined to be 7.1, which is very low and closely matches that of His64. This low $\mathrm{p} K_{\mathrm{a}}$ is most likely necessary to allow efficient proton transfer in both directions between the $\mathrm{Zn}$ ion and the bulk water (Michalczyk et al., 2015).

The first neutron structure of a clinical drug-human enzyme complex was solved using data collected at the PCS, showing the anionic form of the diuretic acetazolamide bound to human CA-II (Fig. 11; Fisher et al., 2012).

\subsection{Diisopropyl fluorophosphatase (DFPase)}

Another LANL mission-critical enzyme is diisopropyl fluorophosphatase (DFPase; 315 amino acids, $35 \mathrm{kDa}$ ). DFPase is a $\mathrm{Ca}^{2+}$-dependent enzyme isolated from the Mediterranean squid head ganglion that is capable of detoxifying a wide range of organophosphorus nerve agents, such as sarin, soman and tabun. These nerve agents act as
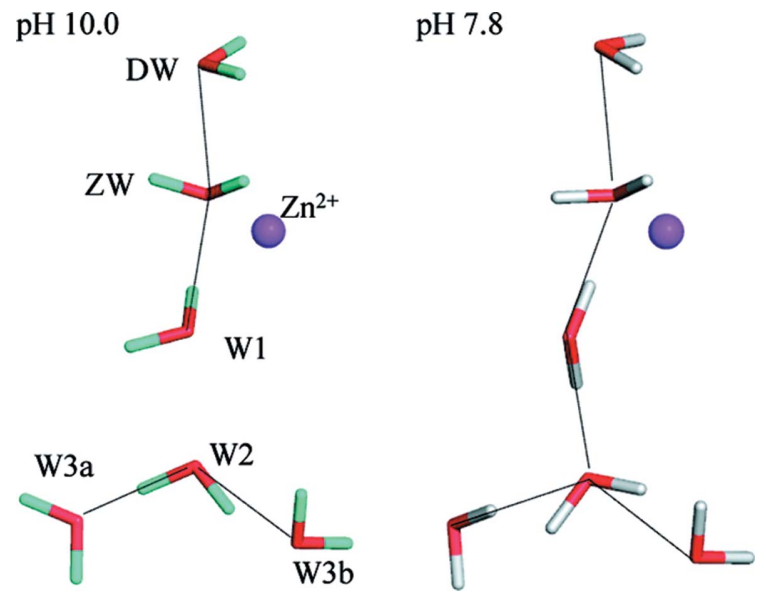

Figure 10

Water-relay network within CA, showing a difference in the orientation of water W1 between $\mathrm{pH} 7.8$ (active) and $\mathrm{pH} 10.0$ (inactive). Reprinted with permission from Fisher et al. (2011), Biochemistry, 50, 9421-9423. Copyright (2011) American Chemical Society.

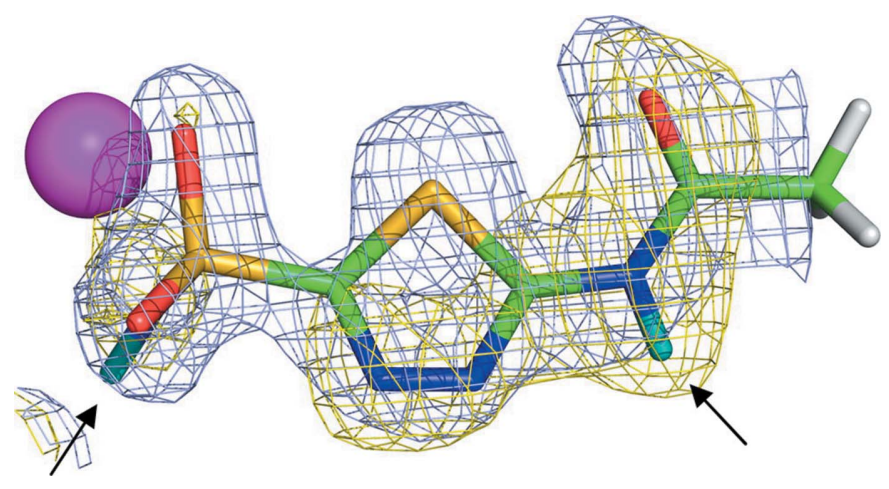

Figure 11

X-ray (gray) and nuclear (yellow) density map for the drug acetazolamide bound to human CA-II. Reprinted with permission from Fisher et al. (2012), J. Am. Chem. Soc. 134, 14726-14729. Copyright (2012) American Chemical Society. irreversible inhibitors of acetylcholinesterase (AChE), blocking the conduction of electrical signals at synapses. DFPase functions by hydrolysis of the $\mathrm{P}-\mathrm{F}$ bond. DFPase is a very stable, heat-tolerant enzyme that can be expressed in large quantities, making it an excellent potential candidate for enzymatic decontamination.

The remarkable properties of the enzyme have been studied using a variety of chemical and structural techniques. A number of X-ray structures of the wild-type enzyme have been solved and nearly 20 site-directed mutants, including a structure of a substrate analogue (DcPPA)-DFPase complex (Scharff et al., 2001; Katsemi et al., 2005; Blum et al., 2006; Melzer et al., 2009; Blum \& Chen, 2010). Labeling experiments under single and multiple turnover conditions in ${ }^{18} \mathrm{O}$-labeled water, combined with mass spectroscopy, suggested a mechanism by which a catalytic aspartic acid (Asp229) was involved in direct nucleophilic attack on the $\mathrm{P}$ atom of the substrate, creating a phosphoenzyme intermediate (Blum et al., 2006). However, based on an ultrahigh-resolution X-ray structure (Koepke et al., 2003), it was also suggested that
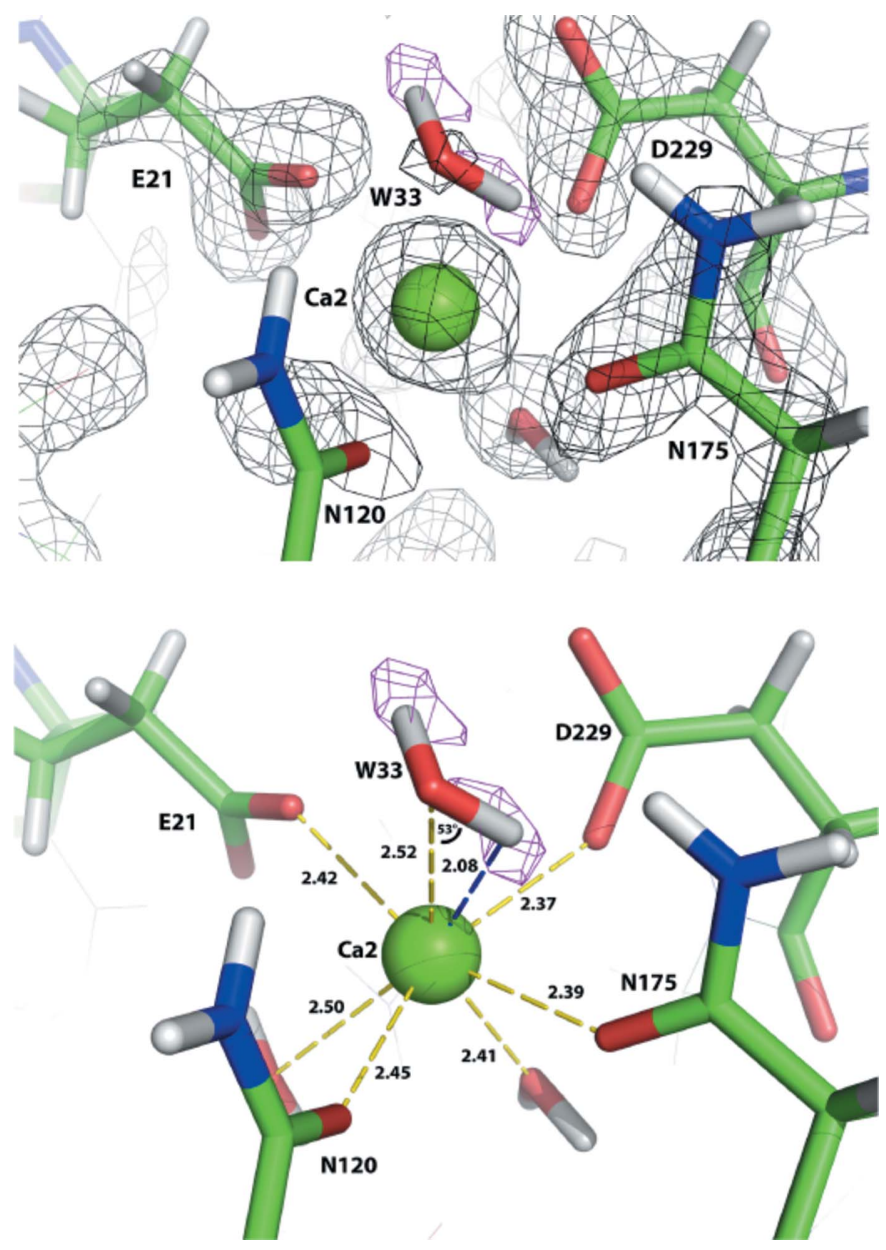

Figure 12

$2 F_{\mathrm{o}}-F_{\mathrm{c}}$ electron (gray) and nuclear $F_{\mathrm{o}}-F_{\mathrm{c}}$ OMIT (magenta) density maps of the DFPase active-site environment. W33 is clearly identified as a water molecule and not a hydroxide, and is situated in an orientation that maximizes hydrogen-bonding interactions. The $\mathrm{Ca}-\mathrm{O}-\mathrm{D}$ angle is $53^{\circ}$. Reprinted with permission from Blum et al. (2009), Proc. Natl Acad. Sci. USA, 106, 713-718. Copyright (2009) National Academy of Sciences. 
the mechanism proceeded through a metal-activated water abstracting a proton to create a hydroxide ion that then attacks the $\mathrm{P}$ atom. To distinguish these possibilities, the neutron structure of DFPase was solved using a $2.2 \AA$ resolution data set collected at the PCS. The resulting structure showed clearly that an active-site solvent atom coordinated by the catalytic calcium is a water molecule and not a hydroxide (Fig. 12). The putative nucleophile Asp229 is deprotonated, consistent with the labeling studies (Blum et al., 2009). Insights from the neutron structure led to the generation of DFPase variants that showed enhanced detoxification properties through engineering stereochemical selectivity to preferably hydrolyze the more toxic stereoisomer of the racemic nerve agents (Melzer et al., 2009). More recent experiments by the PCS staff, together with the Organization for the Prohibition of Chemical Weapons (OPCW) in The Hague, have demonstrated that the proposed mechanism is conserved within the range of G-type nerve agents.

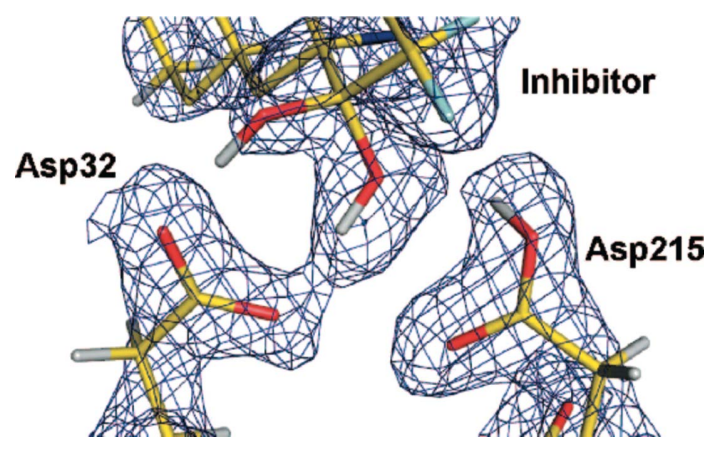

Figure 13

Nuclear density for the active site of the endothiapepsin-inhibitor complex. Asp32 is deprotonated, likely forming a low-barrier hydrogen bond with the gem-diol inhibitor, while Asp215 is protonated, acting as a hydrogen-bond donor to the inhibitor. Reprinted with permission from Coates et al. (2008), J. Am. Chem. Soc. 130, 7235-7237. Copyright (2008) American Chemical Society.
This was also a technical achievement for the PCS, utilizing one of the smallest crystals at the time for a macromolecular diffraction experiment $\left(0.43 \mathrm{~mm}^{3}\right)$ and demonstrating that protein preparation, crystallization and data acquisition could be completed in less than six months (Blum et al., 2007). A second major achievement in the work on the DFPase structure was the use of joint X-ray/neutron refinement, based on a room-temperature X-ray data set collected from a DFPase crystal together with the neutron data.

\subsection{Aspartyl proteases}

Aspartyl proteases are among the major protease families, relying on a pair of aspartic acid residues to catalyze cleavage of the peptide bond. Their mechanism has been studied for many decades, in part owing to their importance in numerous physiological and disease processes, such as hypertension and AIDS. Pepsin is a major digestive enzyme, and perhaps the most studied aspartyl protease, HIV-1 protease, recognizes specific cleavage sites on the HIV polyprotein to cleave it into three component enzymes: protease, reverse transcriptase and integrase.

Although the aspartyl proteases utilize two aspartic acid residues acting in tandem to cleave the substrate, and many aspartyl proteases such as HIV-1 protease are in fact dimeric, the chemical properties of the aspartic acid residues are not identical. Neutron diffraction data on a crystal of the fungal aspartic protease endothiapepsin in complex with a gem-diol inhibitor were collected at the PCS (Fig. 13; Coates et al., 2008). Parallel X-ray data sets were also collected at atomic resolution $(1.0 \AA)$. Bond lengths were used to infer the protonation state of the aspartate residues after removing stereochemical restraints on the aspartates. The nuclear density maps at $2.0 \AA$ resolution point to one (Asp215) of the two catalytic aspartic acids being protonated, with one of the gem-diol $\mathrm{H}$ atoms in an orientation and position consistent with a low-barrier hydrogen bond. The stability of the low-
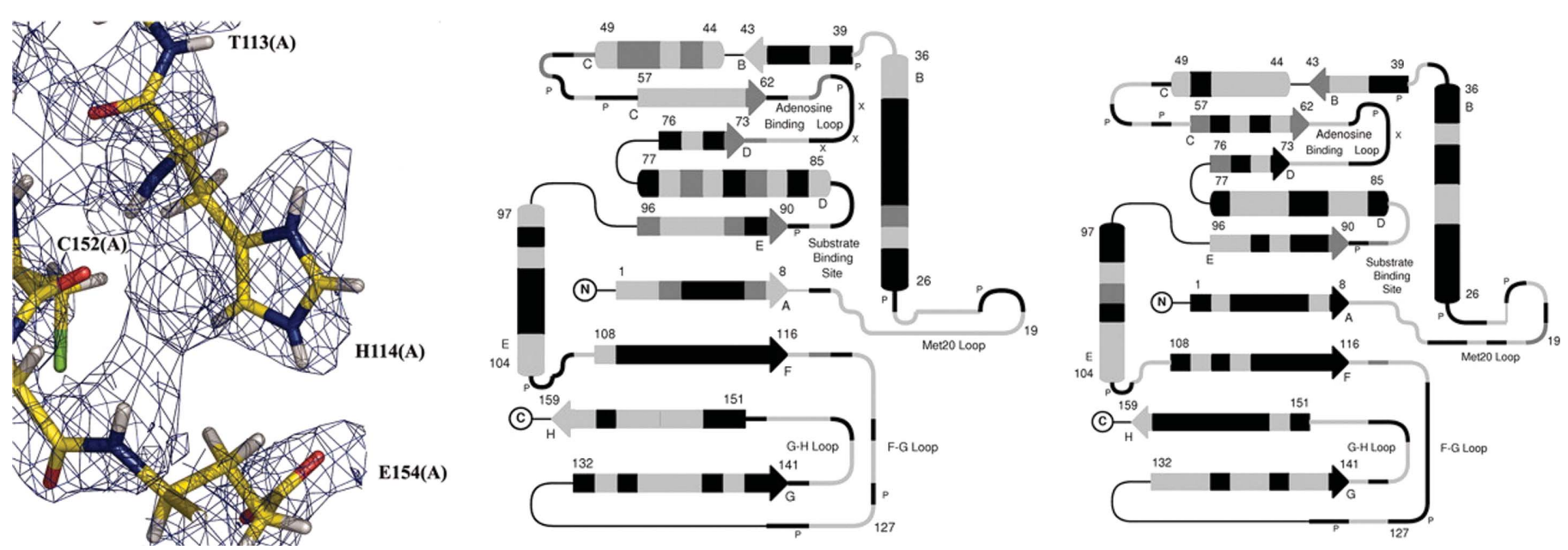

Figure 14

Left, nuclear $2 F_{\mathrm{o}}-F_{\mathrm{c}}$ density for active-site residues, showing double protonation of His114. Middle and right, amide backbone H/D-exchange pattern for the two monomers of DHFR, ranging from gray (exchanged) to black (not exchanged). Reprinted with permission from Bennett et al. (2006), Proc. Natl Acad. Sci. USA, 103, 18493-18498. Copyright (2006) National Academy of Sciences. 
barrier hydrogen bond is thought to offset the strain experienced by the scissile peptide bond when productively bound.

\subsection{Dihydrofolate reductase (DHFR)}

Another enzyme of medicinal interest, dihydrofolate reductase (DHFR), was studied at the PCS. DHFR is an enzyme that is crucial for numerous biosynthetic pathways, catalysing the NADP-dependent reduction of dihydrofolate (CHF) to tetrahydrofolate (THF). THF in turn is an essential cofactor in the biosynthesis of nucleotides as well as selected amino acids. As such, DHFR is the target of several clinical drugs, such as the chemotherapeutic methotrexate and the antimicrobial agent trimethoprim. These drugs block the ability of the cell to synthesize DNA, ultimately leading to cell death. The neutron structure of the E. coli DHFR-MTX complex was solved using data collected at the PCS from a very small crystal of $\sim 0.25 \mathrm{~mm}^{3}$ in volume, revealing bindinginduced protonation on the MTX ring at N1 (Fig. 14; Bennett et al., 2006). This protonation allows an ionic interaction with an uncharged Asp27. The H/D-exchange pattern in the backbone amides reveals that the two monomers of the dimer have similar, but not identical, H/D-exchange properties.

\subsection{Crambin}

The small protein crambin (46 amino acids, $4.7 \mathrm{kDa}$ ), isolated from the seeds of the Abyssinian cabbage (Crambe abyssinica), forms the best ordered macromolecular crystals known, diffracting X-rays to a resolution of $0.38 \AA$. Although no biological function has been attributed to crambin, the extraordinary diffraction properties of crambin crystals have enabled the development of numerous crystallographic techniques, such as native single-wavelength anomalous diffraction (SAD) phasing (Hendrickson \& Teeter, 1981), direct methods, refinement and also biophysical methods such as molecular dynamics. An early study in the 1980s hinted at the excellent neutron diffraction properties of crambin crystals (Teeter \& Kossiakoff, 1984).

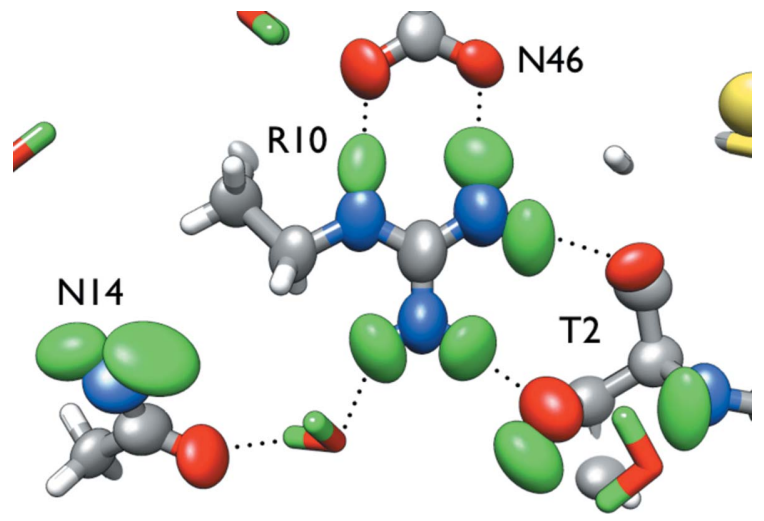

Figure 15

Anisotropic vibrational motions of selected D atoms in crambin. In green are the anisotropic ellipsoids of selected D atoms in crambin, with their respective hydrogen-bonding partners. $\mathrm{N}$ atoms are in blue, $\mathrm{O}$ atoms in red and $\mathrm{C}$ atoms in gray. Reprinted with permission from Chen et al. (2012), Proc. Natl Acad. Sci. USA, 109, 15301-15306. Copyright (2012) National Academy of Sciences.
A new, complete data set was collected from a large $\left(4 \mathrm{~mm}^{3}\right)$ crambin crystal in 2011 at the PCS, yielding observed diffraction beyond $1.0 \AA$ resolution. The unprecedented neutron resolution $(85 \%$ complete to $1.1 \AA$ resolution) allowed the anisotropic analysis of hydrogen atomic motions in a protein for the first time (Fig. 15; Chen et al., 2012). Overall, $\mathrm{H}$ atoms are more anisotropic than their bonded neighbors ( $\mathrm{N}, \mathrm{O}$ and $\mathrm{S})$. The work also reinforced the utility of neutron diffraction to elucidate $\mathrm{H}$-atom positions and hydrogen-bonding networks, which are often ambiguous even in the highest resolution X-ray structures (Fig. 16).

The structure also identified potential $\mathrm{C}-\mathrm{H} \cdots \mathrm{O}$ hydrogenbonding interactions through evidence of partial backbone $\alpha$-hydrogen H/D exchange. Partial exchange of one of the two backbone $\mathrm{H}$ atoms of Gly31 was seen, indicating that the $\mathrm{H}$ atoms were in different chemical environments, in agreement with NMR studies. In collaboration with staff from APS, X-ray
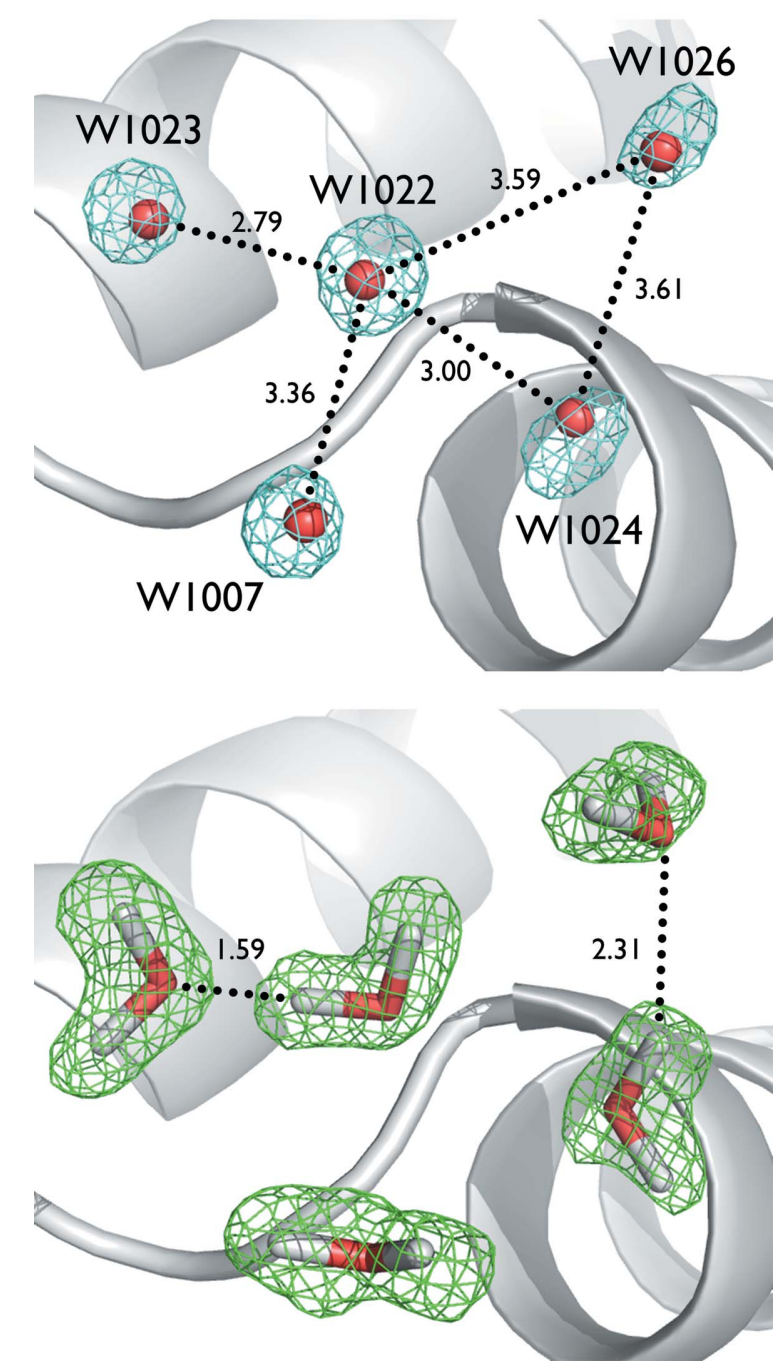

Figure 16

Top, X-ray electron-density map at $0.83 \AA$ resolution showing ambiguous hydrogen-bonding networks in water molecules associated with crambin. Bottom, nuclear density map at $1.1 \AA$ showing the hydrogen-bonding network and clear density for water molecules. Reprinted with permission from Chen et al. (2012), Proc. Natl Acad. Sci. USA, 109, 15301-15306. Copyright (2012) National Academy of Sciences. 
diffraction data were collected from crambin crystals to an unprecedented resolution of $0.38 \AA$, the highest resolution recorded for a macromolecule to date. The data collection required a reconfigured beamline and the use of helium-based cryocooling (Rosenbaum et al., 2015).

Furthermore, the crambin neutron structure yielded perhaps the most accurate structure of the protein and associated solvent atoms to date, which has served as a starting point for theoretical and computational studies on the protein. A number of fundamental questions pertaining to solventstructure and protein-solvent interactions can be answered by future neutron structures, making crambin an exceptional model system for studying these issues.

\subsection{Joint X-ray and neutron refinement}

It was recognized early on that the refinement of neutron structures could be problematic. Neutron diffraction data are generally weak and at a lower resolution than X-ray data. Because of the strong scattering from $\mathrm{H}$ atoms in addition to the heavy elements $(\mathrm{C}, \mathrm{N}, \mathrm{O}, \mathrm{S})$ in proteins, the number of atomic positions being refined greatly increases, and the datato-parameter ratio is typically low. Furthermore, as H/D occupancies are refined in neutron structures, overfitting of data is a major concern. The concept of using X-ray diffraction data to complement and supplement neutron diffraction data was developed in detail in the early 1980s in a seminal set of papers by Coppens, implemented for small molecules in MAUDY (Coppens et al., 1981), and by Wlodawer and Hendrickson, implemented in the least-squares crystallographic refinement program PROLSQ (Wlodawer \& Hendrickson, 1982). Joint refinement was applied to parallel neutron and X-ray data sets collected from crystals of ribonuclease A (Wlodawer \& Sjölin, 1983), BPTI (Wlodawer et al., 1984) and insulin (Wlodawer et al., 1989). In the mid-2000s, joint refinement was incorporated into the commonly used crystallographic refinement programs CNS (as $n C N S$ ) and $P H E N I X$. This project was conducted jointly with Lawrence Berkeley Laboratory (LBL) and has continued at ORNL as part of an NIH-funded project (Adams et al., 2009). The earliest successes of this implementation were the structure refinements of photoactive yellow protein (PYP), endothiapepsin and DFPase using data collected at the PCS (Fisher et al., 2007; Coates et al., 2008; Blum et al., 2009).

This modern implementation of joint neutron and X-ray refinement takes advantage of the maximum-likelihood refinement target function of current crystallographic refinement programs, as opposed to the least-squares target in older programs. In a typical refinement, the two data sets are weighted relative to one another and the progress of the refinement is monitored by $R_{\text {free }}$ values, and the difference between the $R_{\text {free }}$ and $R_{\text {work }}$ values is used to assess the degree of model bias or overfitting.

The joint refinement was found to be especially effective at moderate resolutions in side-chain conformations. In nonperdeuterated structures, the side-chain methyl $\mathrm{H}$ atoms $\left(\mathrm{CH}_{2} / \mathrm{CH}_{3}\right)$ remain unexchanged, and the opposite signs of the
Table 4

Macromolecular neutron crystallography instruments.

\begin{tabular}{ll}
\hline Instrument & Location and source \\
\hline LADI-III & ILL, reactor \\
D19 & ILL, reactor \\
MaNDi & SNS, spallation \\
IMAGINE & HFIR, reactor \\
BioDiff & FRM-II, reactor $\dagger$ \\
iBIX & J-PARC, spallation \\
BIX-3 & JRR-3, reactor \\
BIX-4 & JRR-3, reactor \\
PCS & Lujan Center, spallation \\
\hline
\end{tabular}

$\dagger$ FRM-II uses a monochromatic beam and most often an IP, with a CCD option.

scattering lengths of $\mathrm{C}(+6.64 \mathrm{fm})$ and $\mathrm{H}(-3.74 \mathrm{fm})$ often lead to a 'cancellation' effect, with little visible nuclear density, making it difficult to correctly position the side chains. The electron density, on the other hand, is often quite clear. Thus, by using both X-ray and neutron diffraction data in the refinement, it should be possible to more accurately model the side-chain conformation. In terminal groups such as $\mathrm{ND}_{2}$ on glutamine and asparagine residues, $\mathrm{ND}_{2} / \mathrm{ND}_{3}^{+}$on lysine residues and the guanidinium group on arginine, D atoms are generally invisible in electron-density maps, but they appear as very strong peaks in nuclear density maps. Similarly, solvent molecules exchanged as $\mathrm{D}_{2} \mathrm{O}$ appear as boomerang-shaped nuclear density, while only the $\mathrm{O}$ atom is typically visible in electron-density maps.

The use of electrostatics in joint X-ray/neutron refinement was also investigated using DNA and XI data sets collected at the PCS (Fenn et al., 2011).

\section{Conclusions and outlook}

The PCS was designed to take advantage of the time-of-flight neutrons at the Lujan Center spallation neutron source, coupled with a high-sensitivity ${ }^{3} \mathrm{He}$-based detector, to shorten the data-collection period by an order of magnitude. Whereas the first neutron structure of myoglobin involved data collection over the course of a year, it is now possible to collect a complete neutron data set in less than a month. In exceptional cases, using crystals that are perdeuterated, it is now possible to collect entire data sets in 1-3 d (Meilleur et al., 2013; Munshi et al., 2012). Refinement of neutron diffraction data has been made easier through joint X-ray/neutron refinement methods in programs such as CNS and PHENIX.

These practical advances have made neutron crystallography a more useful tool for understanding protein structure, dynamics and reaction mechanisms. These advances demonstrated at the PCS have helped to drive the development of instrumentation at new beamlines at spallation neutron sources, such as those now available at the SNS, J-PARC and the future ESS. Together with the image-plate technology and the Laue approach driven by work at the ILL (Niimura et al., 1997; Cipriani et al., 1994, 1996; Habash et al., 1997) and now in use at reactor sources such as HFIR, ILL and FRM-II, datacollection times are now much shorter. In addition, perdeuteration of samples along with these developments means 
that it is now possible to accommodate larger proteins and study more complex systems (Table 4; see also Fig. 20 of Blakeley, 2009).

The science highlights presented in this review demonstrate the utility of neutron crystallography in obtaining useful information about the positions of $\mathrm{H}$ (D) atoms at moderate resolution ( $2.5 \AA$ or better). Deuteration of the exchangeable $\mathrm{H}$ atoms in proteins facilitates the study of mobile $\mathrm{H}$ atoms in enzyme mechanisms and the interaction of solvent water molecules and their role in catalysis. In exceptional cases, such as crambin, the ultrahigh-resolution neutron protein structure demonstrated that nearly all of the $\mathrm{H}$ atoms in a macromolecule can be experimentally ascertained, and the anisotropic vibrational characteristics of $\mathrm{D}$ atoms in macromolecules could be observed for the first time.

Over the course of the user program, during which neutrons were available for 4-5 months of the year, the PCS received 220 proposals, with nearly $3000 \mathrm{~d}$ of neutron beam time requested, compared with $1418 \mathrm{~d}$ of delivered beam. As of the time of writing, 21 structures determined at the PCS have been deposited in the PDB, with additional structures currently in the refinement stage. It is expected that even with the recent commissioning and design of new instruments, neutron beam time is expected to remain at a premium.

\section{Acknowledgements}

The authors thank Virginia Unkefer for editing, and the designers, instrument scientists and technical and support staff, past and present, including Benno Schoenborn, Paul Langan, Zoe Fisher, Andrey Kovalevsky, Marat Mustyakimov, Leighton Coates, John-Paul Bacik, Javier Gonzalez, Oksana Gerlits, Gayle Greene, Mary Jo Waltman, Kelly Knickerbocker, Melvin Borrego and Jason Gochanour. We thank Professor John Helliwell for his insightful comments. The PCS user program was funded by the Department of Energy Office of Science (DOE-OBER).

\section{References}

Adams, P. D., Mustyakimov, M., Afonine, P. V. \& Langan, P. (2009). Acta Cryst. D65, 567-573.

Bennett, B., Langan, P., Coates, L., Mustyakimov, M., Schoenborn, B., Howell, E. E. \& Dealwis, C. (2006). Proc. Natl Acad. Sci. USA, 103, 18493-18498.

Blakeley, M. P. (2009). Crystallogr. Rev. 15, 157-218.

Blakeley, M. P., Hasnain, S. S. \& Antonyuk, S. V. (2015). IUCrJ, 2 , 464-474.

Blakeley, M. P., Teixeira, S. C. M., Petit-Haertlein, I., Hazemann, I., Mitschler, A., Haertlein, M., Howard, E. \& Podjarny, A. D. (2010). Acta Cryst. D66, 1198-1205.

Blum, M.-M. \& Chen, J. C.-H. (2010). Chem. Biol. Interact. 187, 373-379.

Blum, M.-M., Koglin, A., Rüterjans, H., Schoenborn, B., Langan, P. \& Chen, J. C.-H. (2007). Acta Cryst. F63, 42-45.

Blum, M.-M., Löhr, F., Richardt, A., Rüterjans, H. \& Chen, J. C.-H. (2006). J. Am. Chem. Soc. 128, 12750-12757.

Blum, M.-M., Mustyakimov, M., Rüterjans, H., Kehe, K., Schoenborn, B. P., Langan, P. \& Chen, J. C.-H. (2009). Proc. Natl Acad. Sci. USA, 106, 713-718.
Blum, M.-M., Tomanicek, S. J., John, H., Hanson, B. L., Rüterjans, H., Schoenborn, B. P., Langan, P. \& Chen, J. C.-H. (2010). Acta Cryst. F66, 379-385.

Bon, C., Lehmann, M. S. \& Wilkinson, C. (1999). Acta Cryst. D55, 978-987.

Chen, J. C.-H., Hanson, B. L., Fisher, S. Z., Langan, P. \& Kovalevsky, A. Y. (2012). Proc. Natl Acad. Sci. USA, 109, 15301-15306.

Cipriani, F., Castagna, J. C., Wilkinson, C., Lehmann, M. S. \& Büldt, G. (1996). Basic Life Sci. 64, 423-431.

Cipriani, F., Dauvergne, F., Gabriel, A., Wilkinson, C. \& Lehmann, M. S. (1994). Biophys. Chem. 53, 5-13.

Coates, L., Tuan, H.-F., Tomanicek, S., Kovalevsky, A., Mustyakimov, M., Erskine, P. \& Cooper, J. (2008). J. Am. Chem. Soc. 130, 72357237.

Coppens, P., Boehme, R., Price, P. F. \& Stevens, E. D. (1981). Acta Cryst. A37, 857-863.

Cuypers, M. G., Mason, S. A., Blakeley, M. P., Mitchell, E. P., Haertlein, M. \& Forsyth, V. T. (2013). Angew. Chem. Int. Ed. 52, 1022-1025.

Cuypers, M. G., Mason, S. A., Mossou, E., Haertlein, M., Forsyth, V. T. \& Mitchell, E. P. (2016). Sci. Rep. 6, 31487.

Dajnowicz, S., Seaver, S., Hanson, B. L., Fisher, S. Z., Langan, P., Kovalevsky, A. Y. \& Mueser, T. C. (2016). Acta Cryst. D72, 892-903.

Fenn, T. D., Schnieders, M. J., Mustyakimov, M., Wu, C., Langan, P., Pande, V. S. \& Brunger, A. T. (2011). Structure, 19, 523-533.

Finer-Moore, J. S., Kossiakoff, A. A., Hurley, J. H., Earnest, T. \& Stroud, R. M. (1992). Proteins, 12, 203-222.

Fisher, S. Z., Aggarwal, M., Kovalevsky, A. Y., Silverman, D. N. \& McKenna, R. (2012). J. Am. Chem. Soc. 134, 14726-14729.

Fisher, S. Z., Anderson, S., Henning, R., Moffat, K., Langan, P., Thiyagarajan, P. \& Schultz, A. J. (2007). Acta Cryst. D63, 11781184.

Fisher, S. Z., Kovalevsky, A. Y., Domsic, J. F., Mustyakimov, M., McKenna, R., Silverman, D. N. \& Langan, P. A. (2010). Biochemistry, 49, 415-421.

Fisher, Z., Kovalevsky, A. Y., Mustyakimov, M., Silverman, D. N., McKenna, R. \& Langan, P. (2011). Biochemistry, 50, 94219423.

Fried, J., Harder, J. A., Mahler, G. J., Makowiecki, D. S., Mead, J. A., Radeka, V., Schaknowski, N. A., Smith, G. C. \& Yu, B. (2002). Nucl. Instrum. Methods Phys. Res. A, 478, 415-419.

Gamble, T. R., Clauser, K. R. \& Kossiakoff, A. A. (1994). Biophys. Chem. 53, 15-25.

Gerlits, O., Wymore, T., Das, A., Shen, C.-H., Parks, J. M., Smith, J. C., Weiss, K. L., Keen, D. A., Blakeley, M. P., Louis, J. M., Langan, P., Weber, I. T. \& Kovalevsky, A. (2016). Angew. Chem. Int. Ed. 55, 4924-4927.

Habash, J., Raftery, J., Weisgerber, S., Cassetta, A., Lehmann, M., Høghøj, P., Wilkinson, C., Campbell, J. W. \& Helliwell, J. R. (1997). Faraday Trans. 93, 4313-4317.

Haertlein, M., Moulin, M., Devos, J. M., Laux, V., Dunne, O. \& Forsyth, V. T. (2016). Methods Enzymol. 566, 113-157.

Harrison, R. W., Wlodawer, A. \& Sjölin, L. (1988). Acta Cryst. A44, 309-320.

Haupt, M., Blakeley, M. P., Fisher, S. J., Mason, S. A., Cooper, J. B., Mitchell, E. P. \& Forsyth, V. T. (2014). IUCrJ, 1, 429-438.

Hazemann, I., Dauvergne, M. T., Blakeley, M. P., Meilleur, F., Haertlein, M., Van Dorsselaer, A., Mitschler, A., Myles, D. A. A. \& Podjarny, A. (2005). Acta Cryst. D61, 1413-1417.

Helliwell, J. R., Habash, J., Cruickshank, D. W. J., Harding, M. M., Greenhough, T. J., Campbell, J. W., Clifton, I. J., Elder, M., Machin, P. A., Papiz, M. Z. \& Zurek, S. (1989). J. Appl. Cryst. 22, 483497.

Hendrickson, W. A. \& Teeter, M. M. (1981). Nature (London), 290, 107-113.

Hirano, Y., Takeda, K. \& Miki, K. (2016). Nature (London), 534, 281-284. 
Howard, E. I., Blakeley, M. P., Haertlein, M., Petit-Haertlein, I., Mitschler, A., Fisher, S. J., Cousido-Siah, A., Salvay, A. G., Popov, A., Muller-Dieckmann, C., Petrova, T. \& Podjarny, A. (2011). J. Mol. Recognit. 24, 724-732.

Howard, E. I., Guillot, B., Blakeley, M. P., Haertlein, M., Moulin, M., Mitschler, A., Cousido-Siah, A., Fadel, F., Valsecchi, W. M., Tomizaki, T., Petrova, T., Claudot, J. \& Podjarny, A. (2016). IUCrJ, 3, 115-126.

Katsemi, V., Lücke, C., Koepke, J., Löhr, F., Maurer, S., Fritzsch, G. \& Rüterjans, H. (2005). Biochemistry, 44, 9022-9033.

Katz, A. K., Li, X., Carrell, H. L., Hanson, B. L., Langan, P., Coates, L., Schoenborn, B. P., Glusker, J. P. \& Bunick, G. J. (2006). Proc. Natl Acad. Sci. USA, 103, 8342-8347.

Koepke, J., Scharff, E. I., Lücke, C., Rüterjans, H. \& Fritzsch, G. (2003). Acta Cryst. D59, 1744-1754.

Kossiakoff, A. A. (1982). Nature (London), 296, 713-721.

Kossiakoff, A. A. (1984). Basic Life Sci. 27, 281-304.

Kossiakoff, A. A., Shpungin, J. \& Sintchak, M. D. (1990). Proc. Natl Acad. Sci. USA, 87, 4468-4472.

Kossiakoff, A. A. \& Shteyn, S. (1984). Nature (London), 311, 582-583.

Kossiakoff, A. A., Sintchak, M. D., Shpungin, J. \& Presta, L. G. (1992). Proteins, 12, 223-236.

Kossiakoff, A. A. \& Spencer, S. A. (1980). Nature (London), 288 , 414-416.

Kossiakoff, A. A. \& Spencer, S. A. (1981). Biochemistry, 20, 64626474.

Kossiakoff, A. A., Ultsch, M., White, S. \& Eigenbrot, C. (1991). Biochemistry, 30, 1211-1221.

Kovalevsky, A. Y., Hanson, L., Fisher, S. Z., Mustyakimov, M., Mason, S. A., Forsyth, V. T., Blakeley, M. P., Keen, D. A., Wagner, T., Carrell, H. L., Katz, A. K., Glusker, J. P. \& Langan, P. (2010). Structure, 18, 688-699.

Kovalevsky, A. Y., Hanson, B. L., Mason, S. A., Yoshida, T., Fisher, S. Z., Mustyakimov, M., Forsyth, V. T., Blakeley, M. P., Keen, D. A. \& Langan, P. (2011). Angew. Chem. Int. Ed. 50, 7520-7523.

Kovalevsky, A. Y., Katz, A. K., Carrell, H. L., Hanson, L., Mustyakimov, M., Fisher, S. Z., Coates, L., Schoenborn, B. P., Bunick, G. J., Glusker, J. P. \& Langan, P. (2008). Biochemistry, 47, $7595-7597$.

Langan, P., Fisher, Z., Kovalevsky, A., Mustyakimov, M., Sutcliffe Valone, A., Unkefer, C., Waltman, M. J., Coates, L., Adams, P. D., Afonine, P. V., Bennett, B., Dealwis, C. \& Schoenborn, B. P. (2008). J. Synchrotron Rad. 15, 215-218.

Langan, P. \& Greene, G. (2004). J. Appl. Cryst. 37, 253-257.

Langan, P., Greene, G. \& Schoenborn, B. P. (2004). J. Appl. Cryst. 37, 24-31.

Langan, P., Lehmann, M., Wilkinson, C., Jogl, G. \& Kratky, C. (1999). Acta Cryst. D55, 51-59.

Langan, P. et al. (2014). Structure, 22, 1287-1300.

Langan, P., Schoenborn, B. P. \& Daemen, L. L. (2001). Proc. SPIE, 4509, 66-72.

Lehmann, M. S., Mason, S. A. \& McIntyre, G. J. (1985). Biochemistry, 24, 5862-5869.

Lehmann, M. S. \& Stansfield, R. F. (1989). Biochemistry, 28, 70287033.

Liu, X., Hanson, B. L., Langan, P. \& Viola, R. E. (2007). Acta Cryst. D63, 1000-1008.

Mahler, G. J., Radeka, V., Schaknowski, N. A., Smith, G. C., Yu, B. \& Zojceski, Z. (1999). IEEE Trans. Nucl. Sci. 46, 1916-1919.

Mason, S. A., Bentley, G. A. \& McIntyre, G. J. (1984). Basic Life Sci. 27, 323-334.

McDowell, R. S. \& Kossiakoff, A. A. (1995). J. Mol. Biol. 250, 553-570.

Meilleur, F., Munshi, P., Robertson, L., Stoica, A. D., Crow, L., Kovalevsky, A., Koritsanszky, T., Chakoumakos, B. C., Blessing, R. \& Myles, D. A. A. (2013). Acta Cryst. D69, 2157-2160.

Melzer, M., Chen, J. C.-H., Heidenreich, A., Gäb, J., Koller, M., Kehe,
K. \& Blum, M.-M. (2009). J. Am. Chem. Soc. 131, 17226-17232.

Michalczyk, R., Unkefer, C. J., Bacik, J.-P., Schrader, T. E., Ostermann, A., Kovalevsky, A. Y., McKenna, R. \& Fisher, S. Z. (2015). Proc. Natl Acad. Sci. USA, 112, 5673-5678.

Mocko, M. \& Muhrer, G. (2013). Nucl. Instrum. Methods Phys. Res. $A, \mathbf{7 0 4}, 27-35$.

Mocko, M., Muhrer, G., Kelsey, C. T., Duran, M. A. \& Tovesson, F. (2011). Nucl. Instrum. Methods Phys. Res. A, 632, 101-108.

Munshi, P., Chung, S.-L., Blakeley, M. P., Weiss, K. L., Myles, D. A. A. \& Meilleur, F. (2012). Acta Cryst. D68, 35-41.

Niimura, N., Minezaki, Y., Nonaka, T., Castagna, J. C., Cipriani, F., Høghøj, P., Lehmann, M. S. \& Wilkinson, C. (1997). Nat. Struct. Biol. 4, 909-914.

Niimura, N. \& Podjarny, A. (2011). Editors. Neutron Protein Crystallography. Oxford University Press.

Petit-Haertlein, I., Blakeley, M. P., Howard, E., Hazemann, I., Mitschler, A., Haertlein, M. \& Podjarny, A. (2009). Acta Cryst. F65, 406-409.

Petit-Haertlein, I., Blakeley, M. P., Howard, E., Hazemann, I., Mitschler, A., Podjarny, A. \& Haertlein, M. (2010). Acta Cryst. F66, 665-669.

Pflugrath, J. W. (1999). Acta Cryst. D55, 1718-1725.

Phillips, S. E. \& Schoenborn, B. P. (1981). Nature (London), 292, 81-82.

Prince, E., Wlodawer, A. \& Santoro, A. (1978). J. Appl. Cryst. 11, 173-178.

Radeka, V., Schaknowski, N. A., Smith, G. C. \& Yu, B. (1996). Basic Life Sci. 64, 57-67.

Rosenbaum, G., Ginell, S. L. \& Chen, J. C.-H. (2015). J. Synchrotron Rad. 22, 172-174.

Savage, H. (1986). Biophys. J. 50, 947-965.

Scharff, E. I., Koepke, J., Fritzsch, G., Lücke, C. \& Rüterjans, H. (2001). Structure, 9, 493-502.

Schmidt, A., Teeter, M., Weckert, E. \& Lamzin, V. S. (2011). Acta Cryst. F67, 424-428.

Schoenborn, B. P. (1969). Nature (London), 224, 143-146.

Schoenborn, B. P. (1996). A Protein Crystallography Station at the Los Alamos Neutron Scattering Center (LANSCE). Report LA-UR-963508.

Schoenborn, B. P. (2010). Acta Cryst. D66, 1262-1268.

Shu, F., Ramakrishnan, V. \& Schoenborn, B. P. (1996). Basic Life Sci. 64, 309-323.

Shu, F., Ramakrishnan, V. \& Schoenborn, B. P. (2000). Proc. Natl Acad. Sci. USA, 97, 3872-3877.

Sukumar, N., Mathews, F. S., Langan, P. \& Davidson, V. L. (2010). Proc. Natl Acad. Sci. USA, 107, 6817-6822.

Teeter, M. M. \& Kossiakoff, A. A. (1984). Basic Life Sci. 27, 335-348.

Tomanicek, S. J., Wang, K. K., Weiss, K. L., Blakeley, M. P., Cooper, J., Chen, Y. \& Coates, L. (2011). FEBS Lett. 585, 364-368.

Wan, Q., Parks, J. M., Hanson, B. L., Fisher, S. Z., Ostermann, A., Schrader, T. E., Graham, D. E., Coates, L., Langan, P. \& Kovalevsky, A. (2015). Proc. Natl Acad. Sci. USA, 112, 12384 12389.

Weber, I. T., Waltman, M. J., Mustyakimov, M., Blakeley, M. P., Keen, D. A., Ghosh, A. K., Langan, P. \& Kovalevsky, A. Y. (2013). J. Med. Chem. 56, 5631-5635.

Wlodawer, A. (1980). Acta Cryst. B36, 1826-1831.

Wlodawer, A. \& Hendrickson, W. A. (1982). Acta Cryst. A38, 239-247.

Wlodawer, A., Miller, M. \& Sjölin, L. (1983). Proc. Natl Acad. Sci. USA, 80, 3628-3631.

Wlodawer, A., Savage, H. \& Dodson, G. (1989). Acta Cryst. B45, 99-107.

Wlodawer, A. \& Sjölin, L. (1982). Proc. Natl Acad. Sci. USA, 79, $1418-1422$.

Wlodawer, A. \& Sjölin, L. (1983). Biochemistry, 22, 2720-2728.

Wlodawer, A., Walter, J., Huber, R. \& Sjölin, L. (1984). J. Mol. Biol. 180, 301-329. 